\title{
The European 2016/17 Drought 0
}

\author{
Ricardo García-Herrera, ${ }^{\mathrm{a}, \mathrm{b}}$ Jose M. GARrido-Perez, ${ }^{\mathrm{a}, \mathrm{b}}$ DAVID BARriopedro, ${ }^{\mathrm{b}}$ \\ CARlos Ordóñez, ${ }^{\mathrm{a}}$ Sergio M. Vicente-Serrano, ${ }^{\mathrm{c}}$ RAQUel Nieto, ${ }^{\mathrm{d}}$ Luis Gimeno, ${ }^{\mathrm{d}}$ \\ ROGERT SORÍ, ${ }^{\mathrm{d}}$ AND PASCAL YIOU ${ }^{\mathrm{e}}$ \\ ${ }^{a}$ Departamento de Ciencias de la Tierra y Astrofísica, Facultad de Ciencias Físicas, \\ Universidad Complutense de Madrid, Madrid, Spain \\ ${ }^{\mathrm{b}}$ Instituto de Geociencias (IGEO), Consejo Superior de Investigaciones Científicas-Universidad \\ Complutense de Madrid, Madrid, Spain \\ ${ }^{\mathrm{c}}$ Instituto Pirenaico de Ecología, Consejo Superior de Investigaciones Científicas, Zaragoza, Spain \\ ${ }^{\mathrm{d}}$ Environmental Physics Laboratory, Facultade de Ciencias Universidade de Vigo, Ourense, Spain \\ ${ }^{\mathrm{e}}$ Laboratoire des Sciences du Climat et de l'Environnement, UMR 8212 CEA-CNRS-UVSQ, Université Paris-Saclay, \\ L'Institut Pierre-Simon Laplace, Gif-sur-Yvette, France
}

(Manuscript received 23 May 2018, in final form 28 February 2019)

\begin{abstract}
We have analyzed the record-breaking drought that affected western and central Europe from July 2016 to June 2017. It caused widespread impacts on water supplies, agriculture, and hydroelectric power production, and was associated with forest fires in Iberia. Unlike common continental-scale droughts, this event displayed a highly unusual spatial pattern affecting both northern and southern European regions. Drought conditions were observed over $90 \%$ of central-western Europe, hitting record-breaking values (with respect to 1979-2017) in $25 \%$ of the area. Therefore, the event can be considered as the most severe European drought at the continental scale since at least 1979. The main dynamical forcing of the drought was the consecutive occurrence of blocking and subtropical ridges, sometimes displaced from their typical locations. This led to latitudinal shifts of the jet stream and record-breaking positive geopotential height anomalies over most of the continent. The reduction in moisture transport from the Atlantic was relevant in the northern part of the region, where decreased precipitation and increased sunshine duration were the main contributors to the drought. On the other hand, thermodynamic processes, mostly associated with high temperatures and the resulting increase in atmospheric evaporative demand, were more important in the south. Finally, using flow circulation analogs we show that this drought was more severe than it would have been in the early past.
\end{abstract}

\section{Introduction}

Droughts are among the main hydroclimatic hazards, but they are very difficult to quantify and spatially map (Wilhite and Pulwarty 2017). They cause large economic losses, water scarcity, some ecological impacts such as decreases in gross primary production (e.g., Ciais et al. 2005), and the occurrence of forest fires (e.g., Pausas 2004). In Europe, the economic losses associated with droughts have been increasing since the early 2000 s, with an average of 6758 million euros per year (Strosser et al. 2012).

Supplemental information related to this paper is available at the Journals Online website: https://doi.org/10.1175/JCLI-D-180331.s1.

Corresponding author: Ricardo García-Herrera, rgarciah@ucm.es
Drought forecasting presents strong limitations in Europe (Mishra and Singh 2011), mostly due to the complex mechanisms and interactions that control these events and their limited representation in the models used for seasonal predictions (Christensen et al. 2013).

Dynamics and land-atmosphere feedbacks play a key role in European drought severity (Seneviratne et al. 2010; Sousa et al. 2011; Vicente-Serrano et al. 2015), with slowly varying components such as sea surface temperature (SST) anomalies being often less important (Schubert et al. 2016). A large part of the atmospheric variability over the Euro-Atlantic sector is controlled by the North Atlantic Oscillation (NAO) and the associated shifts of the eddy-driven jet (Woollings et al. 2010). Given its leading role in European precipitation, large-scale drought episodes in the continent are often associated with the NAO, whose distinctive north-south dipole 
signature promotes droughts in either northern or southern regions. Other important weather patterns in the region are atmospheric blocking (e.g., Barriopedro et al. 2010) and subtropical ridges (e.g., Santos et al. 2009), which pertain to high pressure systems in northern and southern Europe, respectively.

The aforementioned circulation systems modulate the storm tracks over the North Atlantic and the associated moisture fluxes toward the continent on synoptic time scales, therefore exerting a strong influence on precipitation anomalies. As precipitation in a region originates from local evaporation and externally advected moisture sources (Bisselink and Dolman 2008), the assessment of source-sink relationships of atmospheric water vapor constitutes an important tool to diagnose drought episodes. Using different techniques, recent studies have identified the local and remote moisture sources of several European regions (e.g., Bisselink and Dolman 2008; van der Ent et al. 2010; Gimeno et al. 2012; Nieto et al. 2014), allowing us to investigate their role in regional drought events (e.g., Drumond et al. 2017; Stojanovic et al. 2017).

In addition to precipitation-related dynamical mechanisms, drought severity also depends on atmospheric evaporative demand (AED), which is determined by both radiative and thermodynamic components (McVicar et al. 2012). AED may reinforce drought under low soil moisture levels (Hirschi et al. 2011), given suppression of evapotranspiration, and subsequent reduction of latent heat fluxes and enhancement of sensible heat fluxes (Seneviratne et al. 2010; Miralles et al. 2014). Positive feedbacks via increased AED may further reinforce drought severity (Miralles et al. 2019; Teuling 2018).

In this sense, recent studies suggest an increase in drought severity over large regions of southern Europe, associated with a precipitation decline (Hoerling et al. 2012) and mainly increased AED (Vicente-Serrano et al. 2014; Spinoni et al. 2015, 2017). Recently, Stagge et al. (2017) reported regional divergences in the likelihood of droughts over Europe as measured by two drought indices that account for precipitation and the additional role of AED, respectively. They showed that European-wide upward trends in AED over the last decades, driven by increasing temperatures, have enhanced droughts in southern Europe and counteracted the effects of increased precipitation in the north. Gudmundsson et al. (2017) also suggested a possible effect of anthropogenic forcing in the diverging trends of water resources between northern and southwestern Europe, with AED playing a major role. These results suggest the emergence of a climate change signal on the occurrence of European droughts.
In this context, during 2016/17 most of western Europe, from Iberia to the United Kingdom, southern Scandinavia, and Italy, suffered a major drought event. Associated impacts were reported in most of these countries. Crops were severely affected by the resulting reduction in agricultural production, especially for cereals, olives, tomatoes, wine grapes, and almonds in Spain and Italy (Reuters 2017). The agricultural association Coldiretti estimated losses of at least two billion euros for this latter country, where water supply was also a main problem. In fact, 11 of 20 Italian regions asked for an emergency declaration to fight against the drought (BBC 2017a). France also took serious measures to face the drought, since water restrictions affected 74 out of 96 departments in July 2017 (The Connexion 2017). In Portugal, devastating fires led to the evacuation of thousands of people (BBC 2017b) and caused human fatalities (DW 2017). Hydroelectric power production in Spain reached a historical minimum in October (El País 2017a), accumulating a 50\% decrease for the first nine months of 2017 (El País 2017b). This coincided with minimum wind energy production and contributed to raising electricity bills to historical high levels. These adverse conditions were accompanied by outstanding anomalies in regional atmospheric circulation and nearsurface fields (temperature, precipitation, and soil moisture) for most seasons from mid-2016 to mid-2017, as reported by different monitoring centers (e.g., ECMWF 2017) and regular bulletins, such as those released by the WMO RA VI Regional Climate Centre on Climate Monitoring (RCC-CM; www.dwd.de/rcc-cm) and the American Meteorological Society (Bissolli et al. 2017, 2018).

The main goals of this work are 1) to characterize the temporal and spatial extent of the 2016/17 drought in Europe, 2) to investigate the role played by the atmospheric circulation, including the analysis of specific weather systems, and 3) to address the relative contribution of precipitation (including anomalies in the water vapor supply from moisture sources) versus AED, with emphasis on the role of thermodynamic processes to explain the severity of this event.

The paper is structured as follows. Section 2 introduces the data and methods employed in this study. Section 3 characterizes the drought event, considering its severity and spatiotemporal evolution in a historical context. Section 4 describes the regional atmospheric circulation and the prevailing weather systems, with special emphasis on the periods of maximum drought severity. Section 5 addresses the relative roles of precipitation- and AED-related anomalies in the drought severity, and places the event in the context of the ongoing climate change. Finally, section 6 summarizes the main conclusions. 


\section{Data and methods}

\section{a. Drought indices}

As precipitation is the main variable determining the onset, spatial extent, duration, intensity, and end of droughts, this variable was originally included in most drought indices (e.g., Heim 2002). In particular, the standardized precipitation index (SPI) (McKee et al. 1993) has been widely used. This index captures well the multiscalar character of droughts compared to other indices like the Palmer drought severity index (PDSI; Palmer 1965) or its modified self-calibrated version (Wells et al. 2004). However, it only relies on precipitation data and therefore ignores the contribution of evaporative loss in the terrestrial water balance. To overcome this limitation while keeping the multiscalar character of the SPI, we also employ the standardized precipitation-evapotranspiration index (SPEI; VicenteSerrano et al. 2010). The SPEI is based on precipitation and AED, being equally sensitive to both factors (Vicente-Serrano et al. 2015). It is calculated by means of a climatic water balance (precipitation minus AED), which is adjusted with a three-parameter log-logistic distribution (Vicente-Serrano and Beguería 2016). The values can be accumulated at different time scales, following the same approach used for the SPI, and converted to standard deviations with respect to average values.

Here the SPEI has been obtained on a monthly basis at a spatial resolution of $0.25^{\circ}$ from 1979 to 2017. Precipitation data are based on the GPCC dataset (Schneider et al. 2011), which was bilinearly interpolated to $0.25^{\circ}$ from the original $0.5^{\circ}$ spatial resolution. As a measure of AED, we have calculated the reference evapotranspiration $\left(\mathrm{ET}_{0}\right)$ at the same resolution through the FAO-56 Penman-Monteith equation (Allen et al. 1998) by using maximum and minimum temperature from the E-OBS dataset (Haylock et al. 2008) and the remaining variables (10-m wind speed, dewpoint temperature, and sunshine duration) from ERA-Interim (Dee et al. 2011). For comparative purposes and to determine the possible role of AED on the drought severity, we also calculated the monthly SPI at different time scales following the same approach as that used for the SPEI but considering precipitation data only.

\section{b. Moisture sources}

The main moisture sources were identified through the use of the FLEXPART v9.0 Lagrangian model (Stohl et al. 2005). The methodology by Stohl and James (2004, 2005) offers an effective way to characterize the moisture transport and it has been widely used in the literature to analyze droughts for different regions of Europe
(Drumond et al. 2017; Stojanovic et al. 2018; Trigo et al. 2013). FLEXPART can track the air masses residing over a target region backward and forwards in time. To this aim, the atmosphere is homogeneously divided into approximately 2 million parcels (air masses), which are followed along their trajectories every $6 \mathrm{~h}$ using three-dimensional wind information. The model employs ERA-Interim data at 6-h intervals $(0000,0600,1200$, and 1800 UTC), with $1^{\circ} \times 1^{\circ}$ horizontal resolution and 61 vertical levels, from 0.1 to $1000 \mathrm{hPa}$. The rate of change in the water vapor content of a parcel along its trajectory - that is, moisture increases (evaporation $e$ ) minus moisture decreases (precipitation $p$ ) -is measured as the change in specific humidity with time, keeping constant the mass of the parcel. The net flux of the atmospheric column $(E-P)$ is obtained by adding the $e-p$ values for all particles within the column from 0.1 to $1000 \mathrm{hPa}$. This budget is integrated into cycles of 10 days, (E-P)i10, which is the average residence time of water vapor in the atmosphere (Numaguti 1999).

We first performed a backward experiment from the target region affected by the drought to identify its moisture sources, defined as those regions where (E-P)i10 $>0$ for the 1980-2016 period. Following Drumond et al. (2017), a threshold (the 90th percentile of the (E-P)i10 $>0$ values) was used to delimit the source regions where the moisture uptake is most intense. The so-identified sources include continental and oceanic regions. Then, the air parcels over each individual source were tracked forward in time for 1980-2017. The moisture loss over the region of interest accounted for by a given source is given by the absolute value |(E-P)i10 < 0|, which can be considered the contribution of the source to precipitation in the region. For each source and month of the drought period, the moisture loss over the sink was compared to its corresponding climatological value, also derived from the forward experiment. Negative anomalies of $|(E-P) i 10<0|$ indicate a reduction in the loss of atmospheric moisture supplied by a given source over the region of interest and hence an expected precipitation deficit.

\section{c. Atmospheric circulation data}

Daily mean fields of zonal wind $(925-700 \mathrm{hPa})$ and 500-hPa geopotential height (Z500) were extracted from ERA-Interim with $0.75^{\circ} \times 0.75^{\circ}$ resolution for the 1979-2017 period. They have been used to characterize the atmospheric circulation anomalies during the drought event. In addition, we have derived several catalogues and indices for the same period to better link the drought event to specific weather regimes.

First, the daily latitude of the North Atlantic eddydriven jet stream, which is associated with the location of 
the storm tracks, has been determined by applying the method presented by Woollings et al. (2010). This algorithm zonally averages the daily low-level (925$700 \mathrm{hPa})$ zonal wind over a longitudinal sector $\left(0^{\circ}-60^{\circ} \mathrm{W}\right)$ for latitudinal bands between $15^{\circ}$ and $75^{\circ} \mathrm{N}$. Then the resulting zonal-mean wind field is 10-day low-pass filtered to remove features associated with individual synoptic systems. Finally, the daily latitude of the jet is identified as the latitude at which this filtered wind field maximizes.

Anomalies in the jet latitude are often associated with specific weather systems, including high-latitude blocks and subtropical ridges, which push the jet stream southward and northward of its climatological location (e.g., Woollings et al. 2010; Sousa et al. 2018). While occurring at different latitudes, high-latitude blocks and subtropical ridges are associated with midtropospheric high pressure systems and weakening of the low-level atmospheric flow. Atmospheric blocking disrupts the prevailing zonal circulation and produces a split of the storm track north and south of the blocking system, often yielding positive precipitation anomalies in southern Europe and negative anomalies in northern and central areas of the continent (Sousa et al. 2017). Subtropical ridges manifest as narrow bands of positive geopotential height anomalies from subtropical to midlatitude regions and are typically associated with southern European droughts (Santos et al. 2009). Sousa et al. (2018) detail the differences between these two weather patterns. We have used daily Z500 fields and applied a simplified version of the method described by Barriopedro et al. (2006) to detect highlatitude blocks, as well as the methodology of Santos et al. (2009) and Sousa et al. (2018) for the identification of subtropical ridges. High-latitude blocks are defined as large-scale $\left(12.5^{\circ}\right.$ longitude) reversals in the meridional Z500 gradient with a persistence of at least 5 days, while subtropical ridges are detected as regional departures of Z500 above a predefined threshold (the 80th percentile of the 31-day moving climatology). For the analyses presented here, we only consider blocks and ridges occurring within the Euro-Atlantic sector $\left(30^{\circ} \mathrm{W}-30^{\circ} \mathrm{E}\right)$. By construction, there are no days in these catalogues with simultaneous occurrence of high-latitude blocks and subtropical ridges.

\section{Description of the drought event}

Monthly SPEI data are used to characterize the spatial extent, duration, and time scale of the drought event. Our assessment is impact-oriented, focusing on the extended period with the largest water imbalance rather than on hydrological years (the period from 1 October to 30 September), whose definition is biased toward precipitation. Negative SPEI values were registered for all analyzed time scales (from 1 to 12 months) between mid-2016 and mid-2017 over large areas of western and central Europe. The driest conditions occurred from $34.5^{\circ}$ to $60.5^{\circ} \mathrm{N}$ and from $11.5^{\circ} \mathrm{W}$ to $18.5^{\circ} \mathrm{E}$ (Fig. 1, top panels). Figure 1 (bottom) shows the monthly evolution of the SPEI averaged over that region from January 2015 to August 2017 for different time scales. Negative SPEI values propagate from short (i.e., meteorological drought) to long (hydrological drought) scales with a time lag of several months. Accordingly, hydrological droughts are characterized by steady declines in the 12-month SPEI values.

The largest negative SPEI value considering all time scales occurred at the 12-month scale in June 2017 (-1.24; equivalent to the 9-month SPEI in May 2017) and identifies July 2016-June 2017 as the driest 12-month period. The weaker SPEI anomalies on shorter time scales indicate that the drought was prominently hydrological, in agreement with the outstanding impacts in water resources (see the introduction). Dry conditions initiated in July 2016 (the 12-month SPEI equals zero in that month, indicating normal conditions on average over the whole domain for August 2015-July 2016; Fig. 1a) and lasted one year, as shown by the steady decline in 12-month SPEI until July 2017 (the absolute minimum) and some recovery afterward (Fig. 1e). These results indicate that the event can be categorized as a hydrological drought persisting from July 2016 to June 2017 (Fig. 1c). The October 2015-September 2016 (Fig. 1b) and October 2016-September 2017 (Fig. 1d) hydrological years are also shown here for comparison purposes. We note that the October 2016-September 2017 hydrological year yields weaker 12-month SPEI anomalies than the July 2016-June 2017 period, therefore missing the dry spell in August-September 2016 (Figs. 1c,d).

While the severity of the drought event varied in space and time, snapshots of the 12-month SPEI reveal widespread dry conditions for all months of the analyzed period, without prominent regional events (not shown, but see Figs. 1a-d). The spatial pattern of 12-month SPEI values in June 2017 indicates that the drought covered most of the continent (Fig. 2a): $91.7 \%$ of the area of study presented negative SPEI values, $25.3 \%$ of which were record-breaking (with reference to 19792017). The drought episode was particularly severe over northern Iberia, some parts of Italy, France, Germany, the Benelux region, and northwestern Ireland (areas bounded by contour lines in Fig. 2a).

To put this event in perspective, we have represented the evolution of the accumulated 1-month SPEI averaged over the land area displayed in Fig. 2 for the six July-June 12-month periods with most severe droughts, together 
a) Aug 2015 - Jul 2016

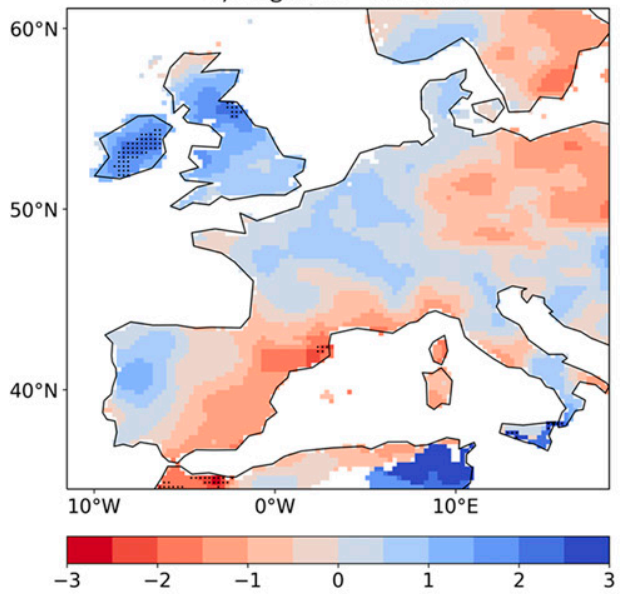

c) Jul 2016 - Jun 2017

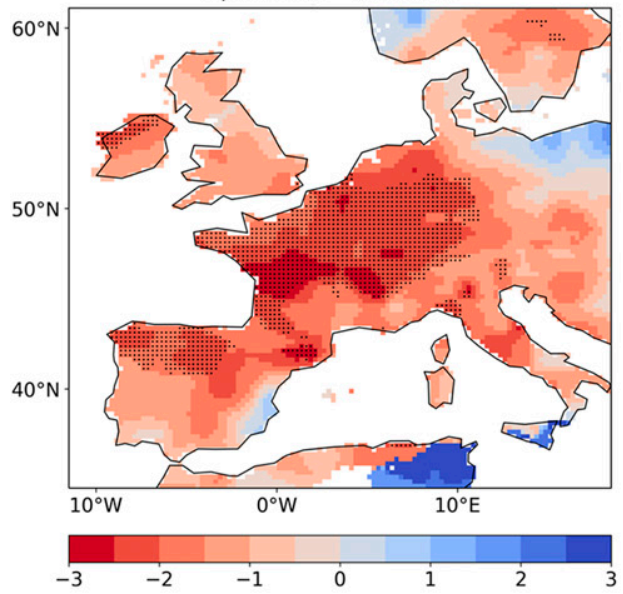

b) Oct 2015 - Sep 2016

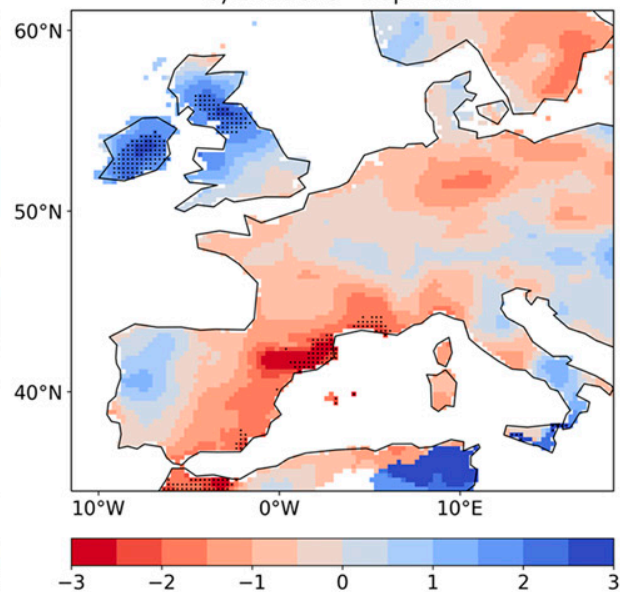

d) Oct 2016 - Sep 2017

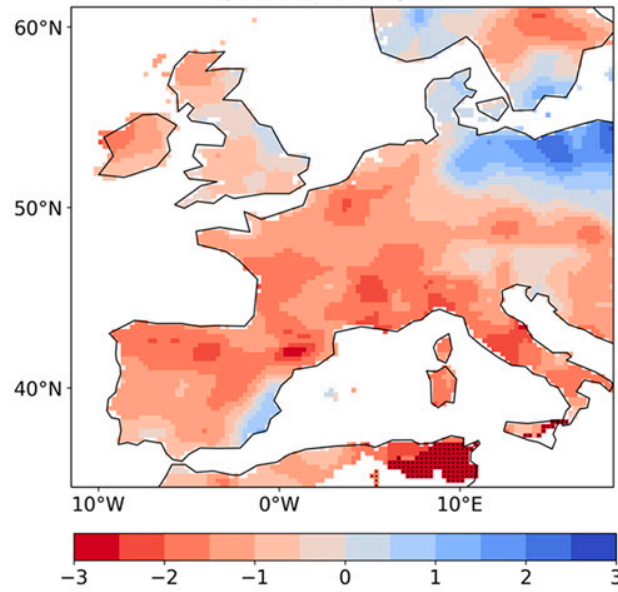

e) Monthly evolution of SPEI

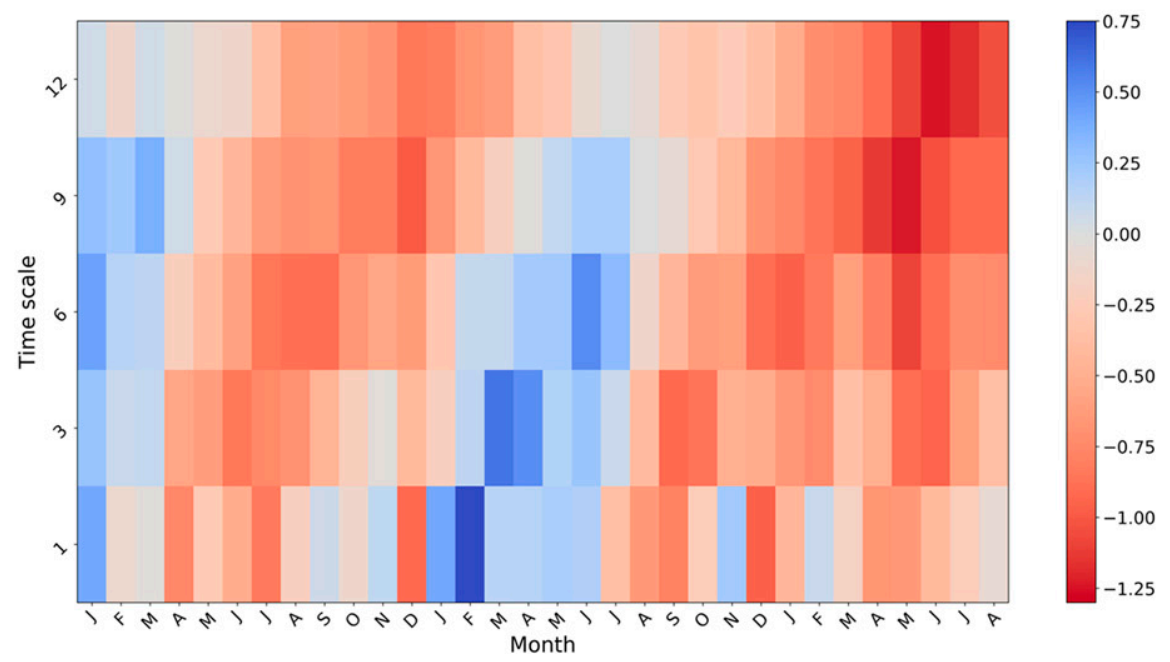

FIG. 1. 12-month SPEI in (a) July 2016, (b) September 2016, (c) June 2017, and (d) September 2017; (b) and (d) represent the accumulated conditions for the 2016 and 2017 hydrological years, respectively, and (c) corresponds to the period of study, while (a) roughly represents the previous year for comparison purposes. Stippling indicates regions with record-breaking values when compared with the period 19792017. (e) Monthly evolution of the SPEI averaged over the area of study shown in (a)-(d) from January 2015 to August 2017 ( $x$ axis) and for time scales ranging from (bottom) 1 month to (top) 12 months. The $t$ month SPEI value of the month $m$ represents the water imbalance for the period $(m-t+1, m)$. 
a) SPEI

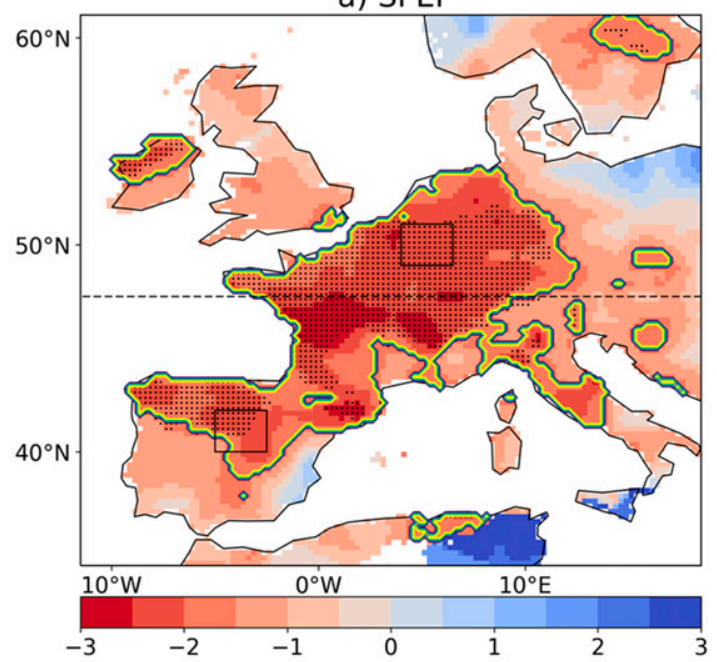

b) SPI

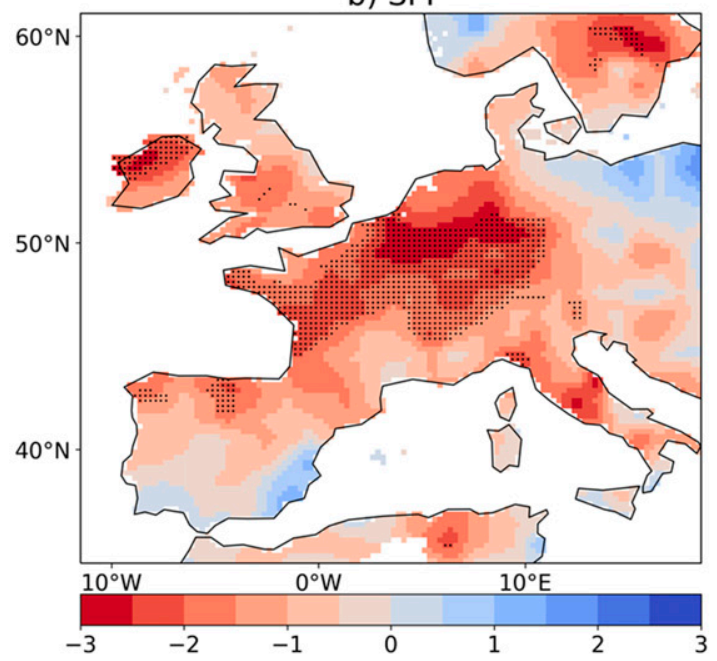

c) Diff SPEI - SPI

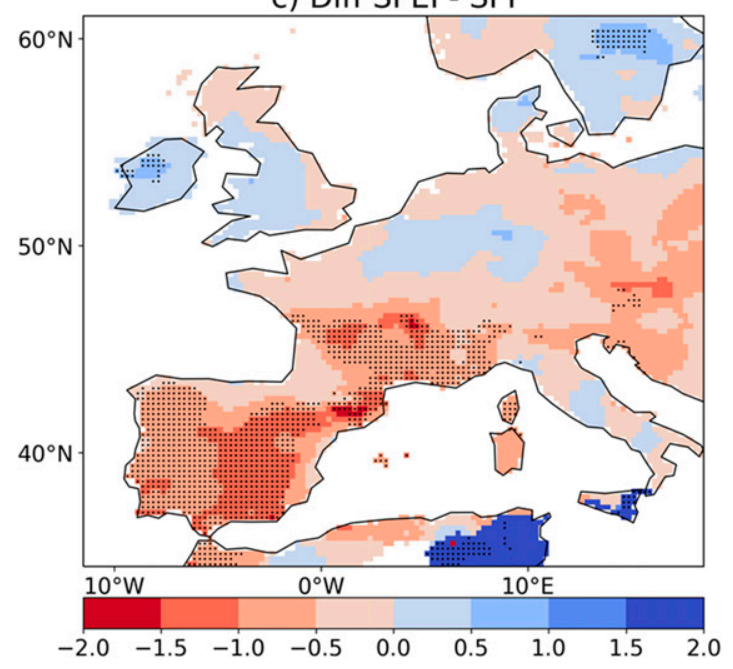

FIG. 2. (a) SPEI, (b) SPI, and (c) the difference between them for June 2017 with a 12-month time scale. Stippling indicates regions with the July 1981-June 2010 climatology, referred to hereafter as 1981-2010 climatology (Fig. 3a). The July 2016June 2017 period is the driest one, breaking previous SPEI records by a wide margin. Accumulated 1-month SPEI values were below -5 at the end of the period of study, whereas in the following driest years they were around -3 , clearly marking the exceptionality of the event. Figure 3a shows that the drought was also outstanding in terms of persistence, with the accumulated values of almost all months in the period laying below the 10th percentile of the climatological distribution. To identify the short-term periods that contributed the most to the long-lasting drought event, the monthly evolution of the 1-month SPEI is shown in Fig. 3c. The period of analysis is characterized by values lower than the 30th percentile (three months below the 10th percentile) of their climatological distribution, except for November 2016 and February and March 2017. Although those three months displayed near-normal and even wet conditions, they were unable to overwhelm the dry conditions on longer time scales (Fig. 1e). Three main dry spells occurred during the drought event: AugustSeptember 2016, December 2016-January 2017, and April-June 2017. For brevity, these periods will also be referred to as summer 2016, winter 2017, and spring 2017.

The main difference from other European droughts (not shown) is that it affected a great range of latitudes, covering most of the area displayed in Fig. 2. In fact, individual countries of northwestern/central and southern Europe, in particular France and, to a lesser extent, Spain or Germany, simultaneously registered recordbreaking negative values of SPEI (see Fig. S1 in the online supplemental material). To stress this unusual pattern, we have divided the area of study into two halves (north and south of $47.5^{\circ} \mathrm{N}$, indicated by the dashed line in Fig. 2a). These areas respectively represent northwestern/central Europe and southern Europe, but we will often refer to them as the northern and southern subregions. The 12-month SPEI has been averaged over both of them separately. This drought is outstanding in both areas, as it ranks as the first and second most severe 1-yr drought event in the southern and northern subregions, respectively, in terms of

with record-breaking values when compared with the period 19792017. The horizontal dashed line at $47.5^{\circ} \mathrm{N}$ marks the division between northwestern/central and southern Europe (also referred to as northern and southern subregions of the drought event). Areas bounded by contours in (a) correspond to regions with SPEI $\leq$ -1.65 . These regions and those bounded by the two black squares have been selected for the analysis of moisture sources in Fig. 8. 
a)

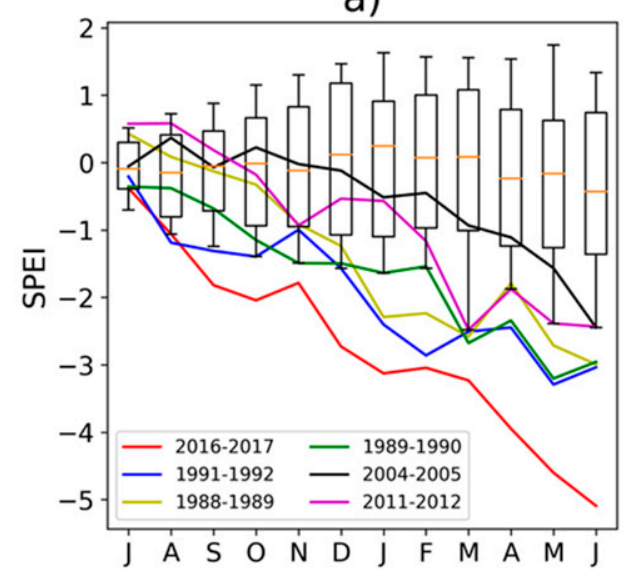

C)

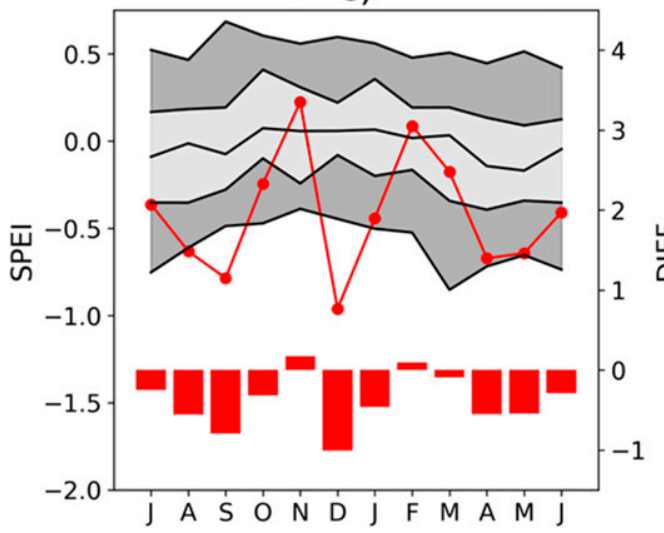

b)

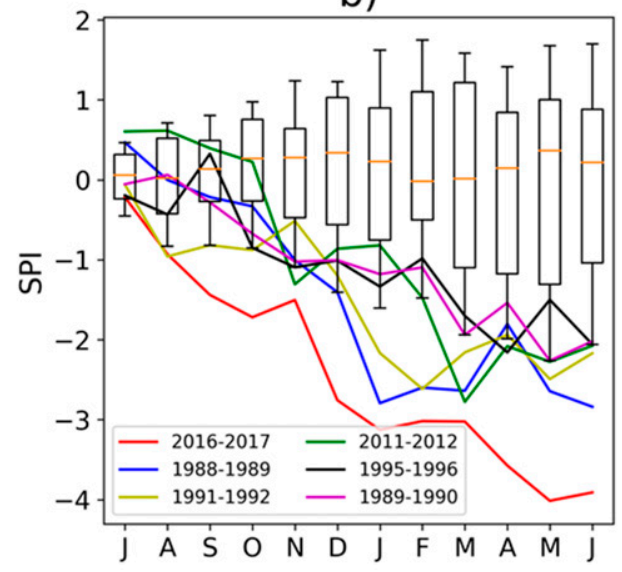

d)

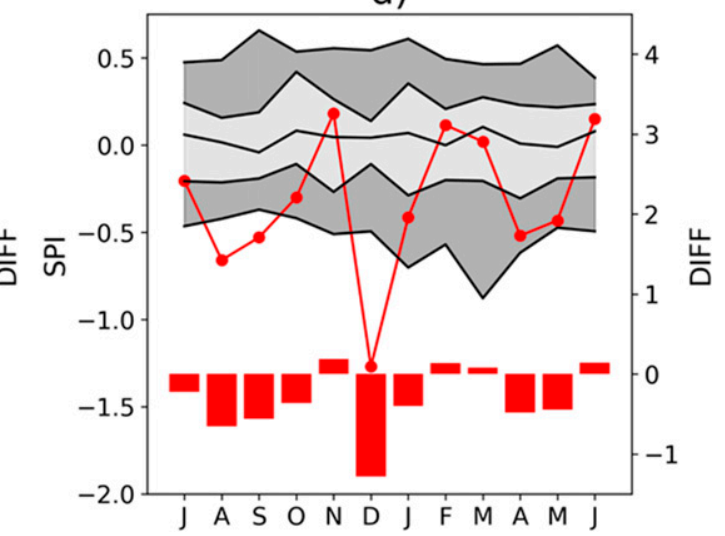

FIG. 3. Mean evolution of the accumulated 1-month time scale (a) SPEI and (b) SPI averaged over the area displayed in Fig. 2a for the 12-month July-June periods of 1981-2010 (boxes), and the 6 years with the most severe droughts in terms of these indices during the 1979-2017 period (colored lines). The lines represent the accumulated monthly value starting from the respective July. The boxes extend from the lower (Q1) to upper (Q3) quartiles, with a horizontal line indicating the median. The whiskers extend from the boxes to show the range of the data, from the 10th to 90th percentiles. Also shown are the climatological (1981-2010) annual cycle of monthly (c) SPEI and (d) SPI averaged over western Europe, with the dark (light) shaded areas comprising the 10th-90th (30th-70th) percentiles, and the median in between. The red lines represent the time series of monthly SPEI and SPI for the July 2016-June 2017 period (left $y$ axis), and the bars show the differences of those monthly values with respect to their climatological means (right $y$ axis).

negative SPEI values. The monthly evolution of the 12month SPEI is also similar in these subregions (Fig. S2). As the simultaneous occurrence of northern and southern droughts is uncommon in Europe, our results confirm the unusual spatial distribution of this event. A more detailed inspection of this unusual spatial distribution and the underlying causes requires an assessment of the atmospheric circulation, which is provided in the next section.

\section{Atmospheric circulation}

Figure $4 \mathrm{a}$ illustrates that the standardized anomalies of Z500 during the drought event were significantly positive at the $95 \%$ confidence level over most of the region, indicating an unusual recurrence and/or amplitude of high pressure systems. Record-breaking values are concentrated in an area encompassing Great Britain to the north and Iberia to the south, and extending eastward to Poland. This pattern is associated with an extreme weakening of the atmospheric circulation, as indicated by the persistent negative zonal wind speed anomalies found in the lower troposphere over the same domain and period (not shown). Different synoptic structures could have contributed to the anomalously weak circulation over the area. In fact, similar analyses for each season of the 2016/17 drought event reveal a variety of regional circulation patterns (Fig. S3). 
a) Z500

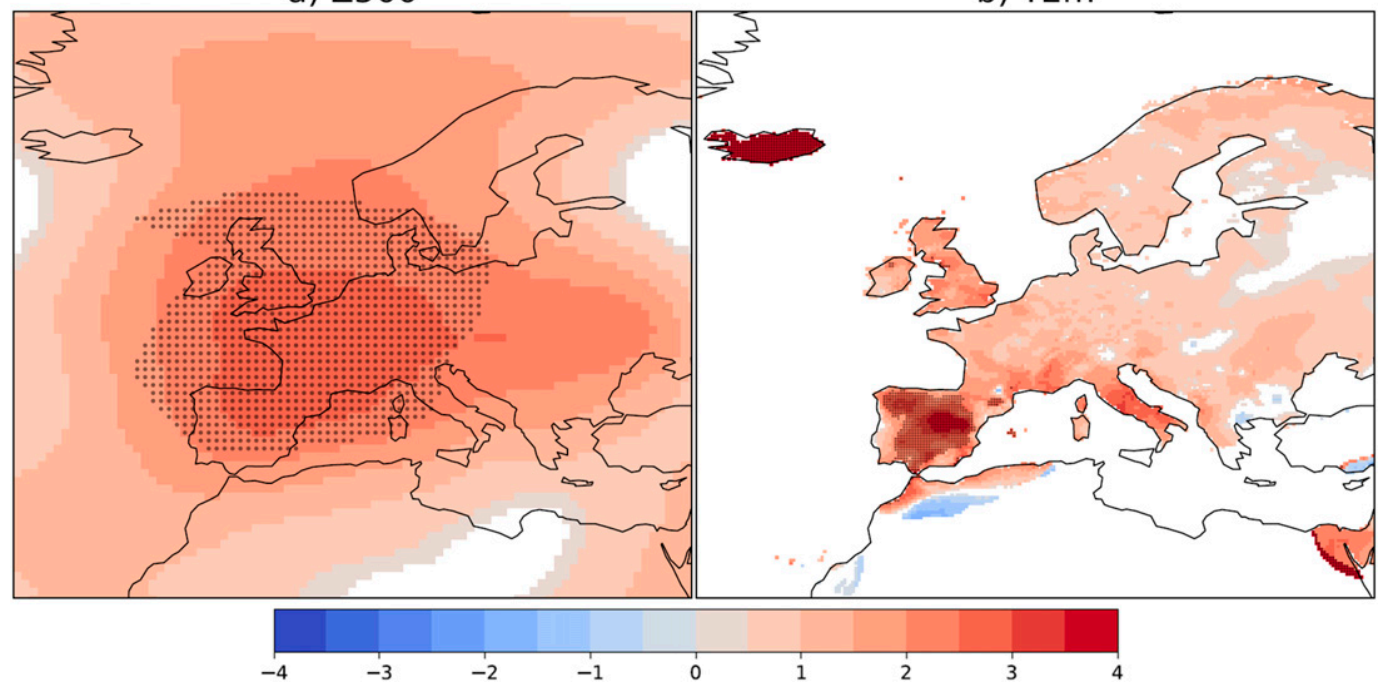

FIG. 4. Standardized anomalies (dimensionless) of (a) 500-hPa geopotential height (Z500) and (b) 2-m temperature during July 2016-June 2017 with respect to the climatology (July 1981-June 2010). Anomalies are shown only when they are significant at the $95 \%$ confidence level (two-tailed $t$ test). Stippling indicates record breaking values for the 1979-2017 period. Data sources: ERA-Interim for Z500 and E-OBS for 2-m temperature.

With the possible exception of the dry spell in summer 2016, which featured an outstanding positive phase of the summer northern annular mode (NAM; Ogi et al. 2004), the large-scale modes of atmospheric variability did not display prominent seasonal anomalies for the driest periods of the event (not shown). These results stress the need for a regional assessment on a monthly basis. Previous studies have also reported that the atmospheric circulation patterns associated with severe European droughts vary across seasons and regions (Fleig et al. 2011) and among individual events (Schubert et al. 2016).
To uncover the nature of the weather systems responsible for the conspicuous Z500 anomalies, we first focus on the North Atlantic jet stream. Figure 5a illustrates the evolution of the monthly mean jet latitude during the drought event. Overall, the jet displayed substantial meridional displacements from its climatological position, and large intermonthly variability, with recurrent alternating shifts to northward and southward locations. Meridional excursions of the jet on monthly time scales have been related to the occurrence of specific anomalous weather systems. In particular, high-latitude blocks involve northward and more commonly southward
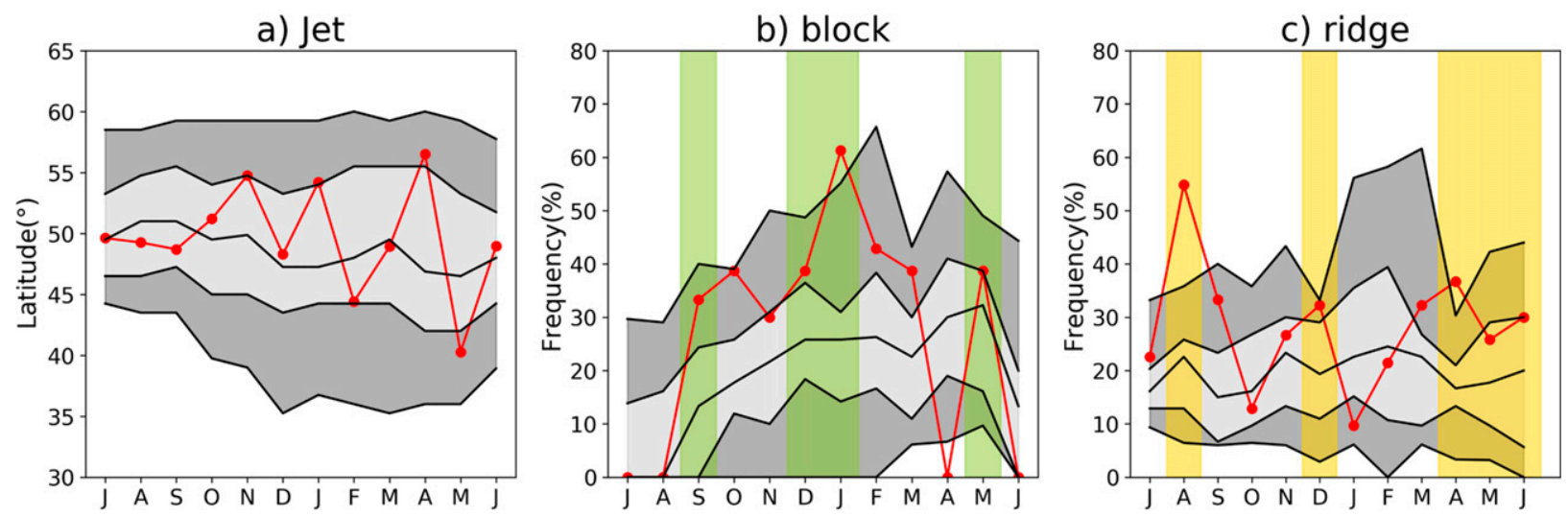

FIG. 5. Climatological (1981-2010) annual cycle of (a) the jet latitudinal position and the monthly frequencies of (b) high-latitude blocks and (c) subtropical ridges, with the dark (light) shaded areas comprising the 10th-90th (30th-70th) percentiles and the median in between. The red lines represent the time series of the monthly mean jet latitude and the monthly frequencies of blocks/ridges for July 2016-June 2017. Green (yellow) shading is used to highlight the months with the most severe drought conditions, according to the SPEI, in the northern (southern) half of the region shown in Fig. 2a (see also Table S1). 
shifts of the jet (e.g., Woollings et al. 2018), while subtropical ridges are more often associated with northward jet migrations (e.g., Sousa et al. 2018).

Therefore, we next turn our attention to ridges and blocks. Figures $5 \mathrm{~b}$ and $5 \mathrm{c}$ display the monthly frequencies of blocks and ridges during the drought event, together with their respective climatologies. Blocks exhibited high variability with monthly frequencies ranging from 0 to exceeding the 90th percentile. Excluding the summer months, when blocks are climatologically rare in the region, their monthly frequency was close to or even above the 70th percentile throughout the rest of the period, with the exception of April 2017. On the other hand, ridges were consistently present over the region during the whole event, with seven months above the 70th percentile and record-breaking occurrence during August 2016. Although blocks and ridges were recurrent through the analyzed period, the former dominated the winter dry spell, and the latter were relatively more frequent during summer 2016 and spring 2017.

Therefore, several weather systems were involved in the drought event and their distinctive latitudinal signatures further suggest different dynamics behind the dry conditions in the northern and southern subregions. To test this hypothesis [i.e., that blocks (ridges) played a dominant role in northern (southern) subregions], we have examined the driest months for each sector separately (see Table S1 in the supplemental material). The months with prevailing southern European drought are considered as those with average 1-month SPEI below -0.55 only in the southern region (August 2016, April 2017, and June 2017), whereas the months with northwestern/central European drought are those with SPEI below that value only in the northern region (September 2016 and January 2017). Only two months (December 2016 and May 2017) show extreme drought conditions simultaneously in both subregions. Although in general drought severity was more pronounced over the northern (southern) subregion in winter 2017 (summer 2016 and spring 2017), there are no successive months with severe drought in only one region, indicating that the event cannot simply be explained as the superposition of independent regional droughts.

Figures $6 \mathrm{a}-\mathrm{c}$ display the Z500 anomalies (contour lines) and SPEI composites (shaded areas) for the months with extreme drought in northern, southern, and both subregions, respectively. Note that, as there is considerable intermonthly variability in the atmospheric circulation over the Euro-Atlantic sector, the Z500 anomalies have first been calculated with respect to the 1981-2010 climatology of each month and then averaged over the months considered. The results are similar if these anomalies are normalized by the interannual standard deviation of each month (not shown). Figure 6a reveals a typical blocking pattern for the months with northern drought, with the center of the positive $\mathrm{Z} 500$ anomalies north of $50^{\circ} \mathrm{N}$. For the months with southern drought, the Z500 anomalies display a subtropical ridge pattern, but with the maximum positive anomalies slightly displaced northward from its usual latitude (e.g., Sousa et al. 2018). The frequency of blocks (ridges) was over the 90th percentile of its climatological distribution for months with prevalent northern (southern) drought, as shown in Fig. 6d (Fig. 6e). Severe drought conditions occurring simultaneously in both regions were associated with positive Z500 anomalies over most of the continent, with their center too northerly for ridges and too southerly for blocks (Fig. 6c), in agreement with an enhanced occurrence of (and/or transitions between) both systems (Fig. 6f). Some of these weather systems were record-breaking in persistence and/or intensity, triggering other exceptional extremes such as the June 2017 mega-heatwave (Sánchez-Benítez et al. 2018).

Therefore, drought severity in the southern region is well explained by the high frequency of subtropical ridges, while recurrent high-latitude blocks largely accounted for the drought conditions in the north. A detailed monthly analysis (see Table S1) confirmed the link between drought severity in the northern (southern) region and high-latitude blocks (subtropical ridges), with only few exceptions. The most prominent examples occurred in October 2016 and March 2017. In the former, the increased blocking frequency was not associated with anomalously negative SPEI values for the northern subregion (Table S1) because the blocking center was displaced significantly northward from its climatological location (Fig. 7c), yielding positive Z500 anomalies over Scandinavia (Fig. 7a). On the other hand, March 2017 was characterized by increased frequencies of blocking and ridges, but comparatively weak negative SPEI values in the northern and southern subregions. This is explained by a highly transient and contrasting behavior during this month, characterized by weak subtropical ridges (Fig. 7d) and blocks, alternating with other patterns that displayed small positive Z500 anomalies over the affected area (not shown). All in all, this resulted in relatively small monthly mean anomalies (Fig. 7b).

As a consequence, the western European drought event largely resulted from an unusual alternating monthly sequence of subtropical ridges and high-latitude blocks, favoring drought conditions in the southern and northern subregions. Atmospheric dynamics is known to play a major role in extreme events, as it provides the immediate 
a) Z500\& SPEI

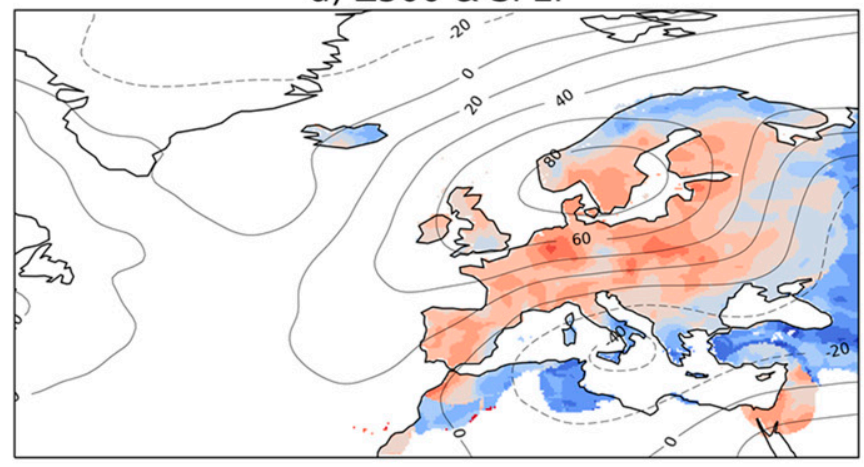

b) Z500 \& SPEI

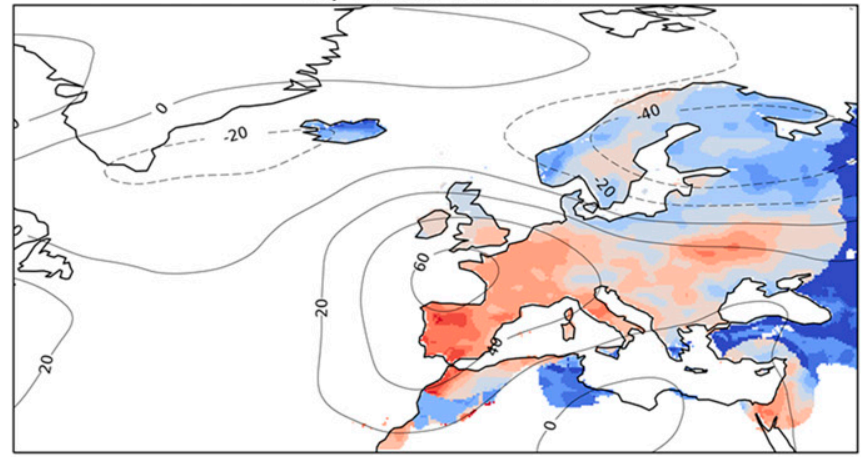

c) Z500 \& SPEI
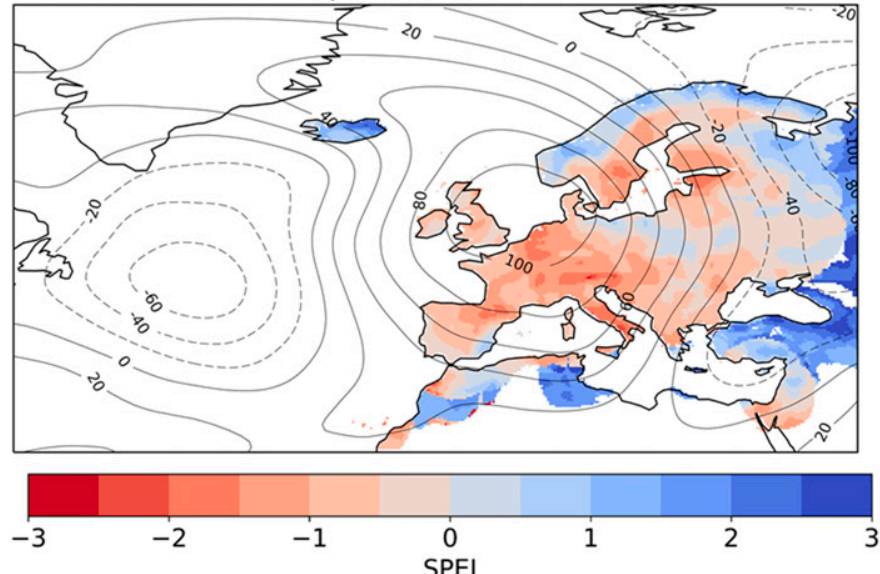

d)

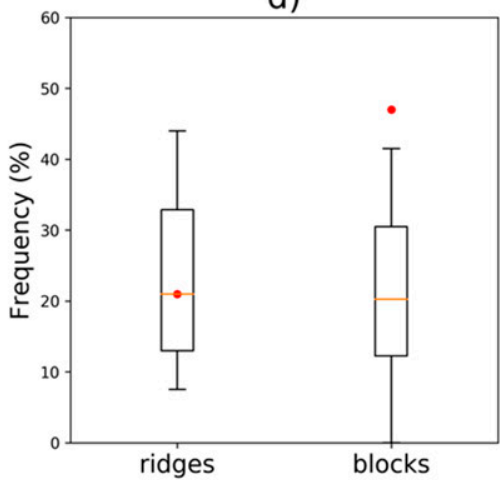

e)
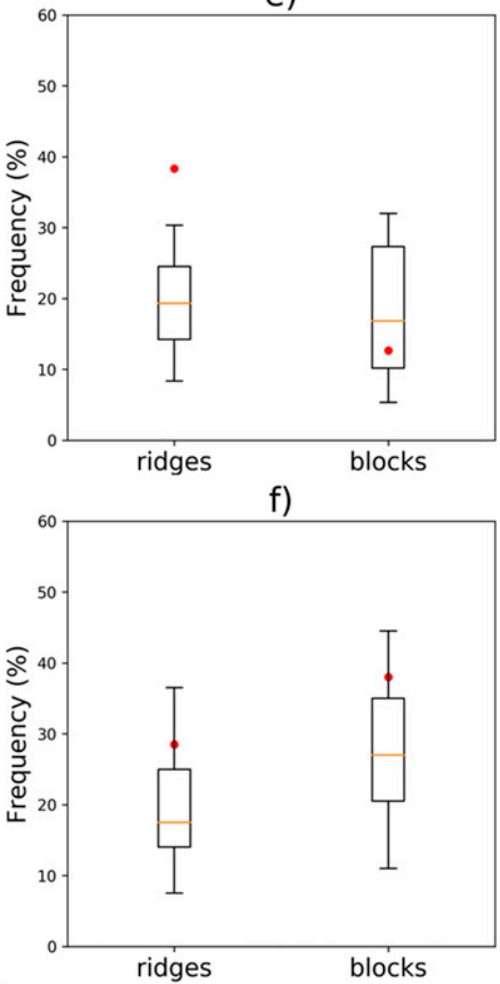

FIG. 6. Mean Z500 anomalies (m, contours) for the months with prevalent drought severity in (a) northern (September 2016 and January 2017), (b) southern (August 2016, April and June 2017), and (c) both northern and southern (December 2016 and May 2017) subregions. Anomalies are calculated with respect to the 1981-2010 climatology of Z500 for such months. Shading displays the mean 1-month time scale SPEI for the same months. Also shown are average frequencies of ridges and blocks during the months with prevalent drought severity in (d) northern, (e) southern, and (f) both northern and southern regions (red dots). Boxplots show the frequency distribution for the same months during the 1981-2010 period. The boxes extend from the lower (Q1) to upper (Q3) quartiles, with a horizontal line indicating the median. The whiskers extend from the boxes to show the range of the data, from the 10 th to the 90 th percentiles.

forcing for triggering near-surface anomalies. In particular, these weather regimes drive precipitation and temperature anomalies over large areas of Europe, as well as departures in other fields relevant for SPEI drought conditions, such as incoming sunshine radiation (Sousa et al. 2017, 2018). In the following section we disentangle the relative roles of precipitation and AED in the drought event. 
a) Oct 2016

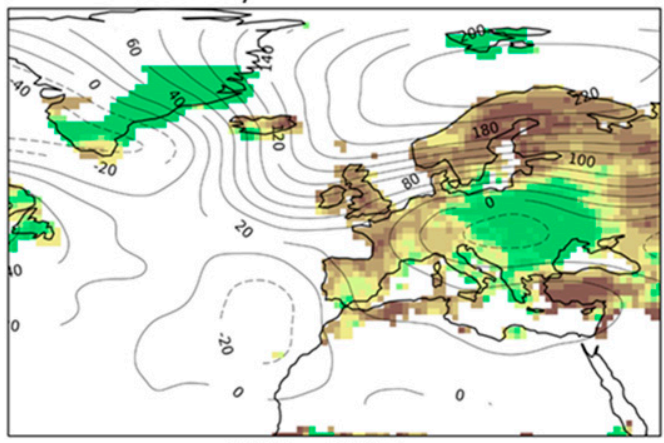

b) Mar 2017

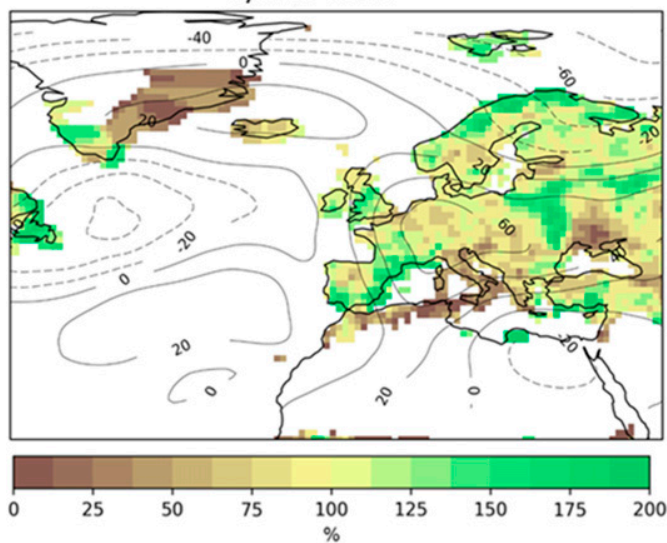

c) Oct 2016 - Block

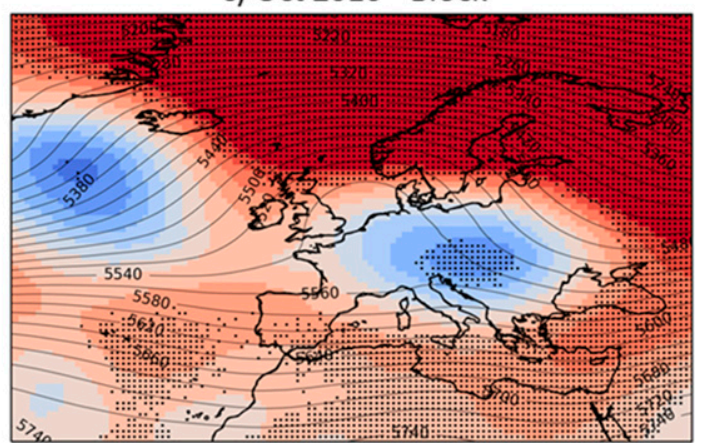

d) Mar 2017 - Ridge

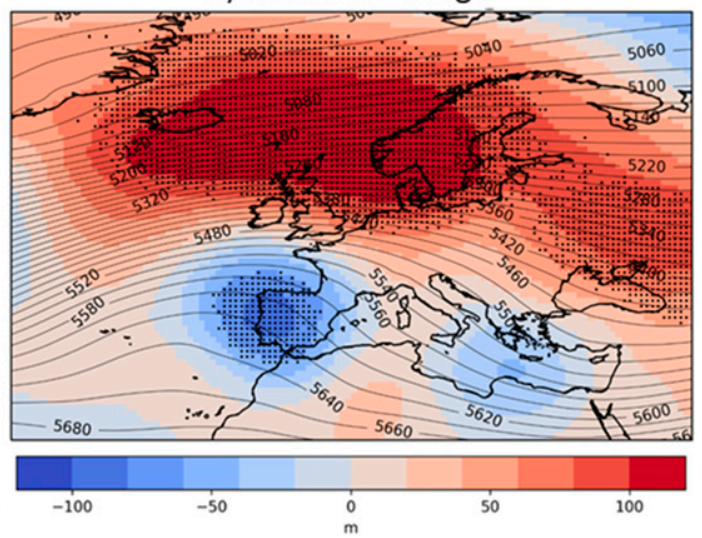

FIG. 7. (a),(b) Monthly anomalies with respect to the 1981-2010 climatology of Z500 (m; lines) and monthly precipitation percentage of the 1981-2010 normals (colored shading) for, respectively, October 2016 and March 2017. Precipitation data come from GPCC and are only shown for areas with climatological monthly rainfall amounts above $20 \mathrm{~mm}$. (c),(d) Synoptic conditions for, respectively, October 2016 and March 2017. Contours depict the 1981-2010 climatology of Z500 (m) for days with blocks [in (c)] and ridges [in (d)]. Shading displays the mean Z500 anomalies with respect to that climatology for days with such patterns during the mentioned months. Stippling indicates regions where anomalies are statistically significant at the $95 \%$ confidence level (determined through a 1000-trial bootstrap resampling method).

\section{The roles of precipitation and AED}

\section{a. Precipitation-related anomalies}

As a first approach to account for the contribution of precipitation anomalies to the drought event, we repeated the previous analyses for the SPEI presented in Figs. 2 and 3, but using the SPI instead. The results indicate some appreciable differences. First, despite the similar spatial distribution, overall the drought signal is reduced for the SPI (Fig. 2b). Although July 2016June 2017 remains as record-breaking in terms of SPI through most of the 12-month period (Fig. 3b), the difference in the accumulated 1-month SPI between June 2017 and the second driest year is not as large as found for the SPEI. The driest months of the drought are the same for SPI and SPEI, but their monthly anomalies diverge (Figs. 3c,d). In particular, the SPI indicates remarkably wetter conditions than the SPEI in some of the warm months (e.g., September 2016 and June 2017) and relatively drier conditions in some cold months (e.g., December 2016). In spite of these differences, the results confirm an important role of precipitation in the SPEI when the entire region is considered. Note, however, that the SPI indicates drier conditions in the northern than in the southern half of the domain, as opposed to the SPEI, thus suggesting a larger contribution of precipitation deficits to the drought severity in northwestern/central Europe (Figs. 2a,b).

To better understand the origin of the precipitation anomalies during the drought event, we analyzed the moisture loss over the target region (TR), herein defined as those areas with 12-month SPEI $\leq-1.65$ (the regions bounded by contours in Fig. 2a). This threshold identifies regions where droughts of that severity would recur with a probability of $5 \%$, that is, once every 20 years. In addition, we have selected two additional boxes 
(Fig. 2a) of similar size but with different precipitation regimes and moisture sources. The southern box is located over the Iberian Peninsula $\left(40^{\circ}-42^{\circ} \mathrm{N}, 5.0^{\circ}-2.5^{\circ} \mathrm{W}\right)$ and the northern box comprises an area between France and Germany $\left(49^{\circ}-51^{\circ} \mathrm{N}, 4.0^{\circ}-6.5^{\circ} \mathrm{E}\right)$. The choice of these regions is further supported by the differences between their SPEI and SPI values, as the northern box displays drier conditions in the SPI than in the SPEI, while the opposite occurs for the southern one (Figs. 2a,b).

We first determined the annual-mean climatological moisture sources for these three regions. The annual cycles of the moisture contribution from each source (in percentage with respect to total moisture from all sources) are shown in Fig. S4. For all regions, the oceanic moisture supply is higher than the continental one, and the Atlantic Ocean represents the dominant source. However, there are some differences between the small boxes, with the continental and Mediterranean (Atlantic) contribution being much higher in the southern (northern) box. As for the TR, the Atlantic Ocean accounts for more than $60 \%$ of the total moisture input, followed by the Mediterranean Sea, with climatological contributions below $15 \%$.

Figure 8 shows the accumulated monthly anomalies of $|(\mathrm{E}-\mathrm{P}) \mathrm{i} 10<0|$ over the drought period for selected moisture sources of the three areas. Negative (positive) anomalies of $|(\mathrm{E}-\mathrm{P}) \mathrm{i} 10<0|$ should be interpreted as a reduced (enhanced) moisture loss of the atmospheric column over the region of interest, as compared to climatology, that is, a precipitation deficit (surplus). The evolution of the accumulated 1month SPEI averaged over each region is also shown in bars. For the TR, the results indicate a marked reduction in the moisture supply from the Atlantic Ocean, with accumulated values at the end of the period as low as $67 \%$ of those expected from the climatology (blue squares in Fig. 8a). Most of the remaining sources also displayed an anomalous but much weaker decrease in their moisture input to TR. For example, the contribution of the Mediterranean (the second most important climatological source for TR) was around $90 \%$ of its climatological value. Interestingly, the accumulated moisture anomalies from the Atlantic and their evolution are in good agreement with those of the 1-month SPEI averaged over TR (Fig. 8a, bars). For example, the largest deficit in moisture supply from the Atlantic occurred in December 2016, when the SPEI averaged over TR reached its minimum value. Actually, the Atlantic is the source with the largest correlation between the nonaccumulated series of moisture anomalies and 1-month time scale SPEI during the drought period $(r=0.69, p<0.02)$, stressing the major control of this source.

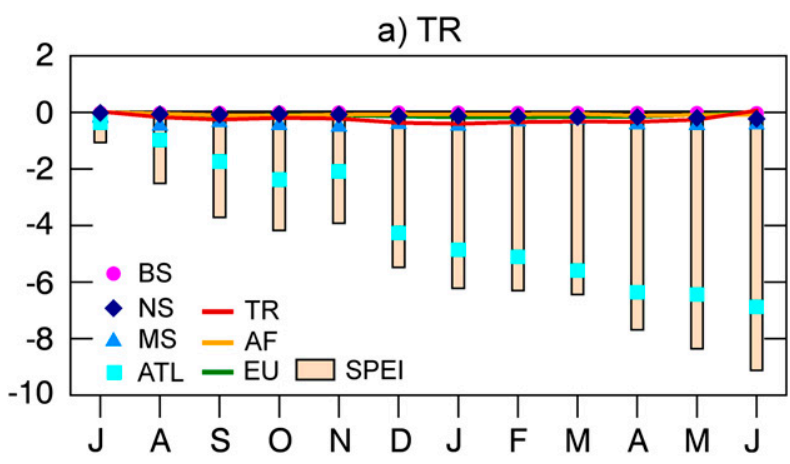

b) northern box

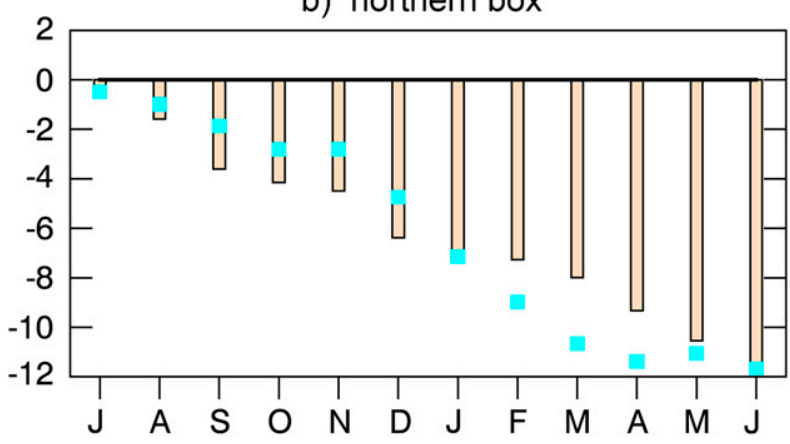

c) southern box

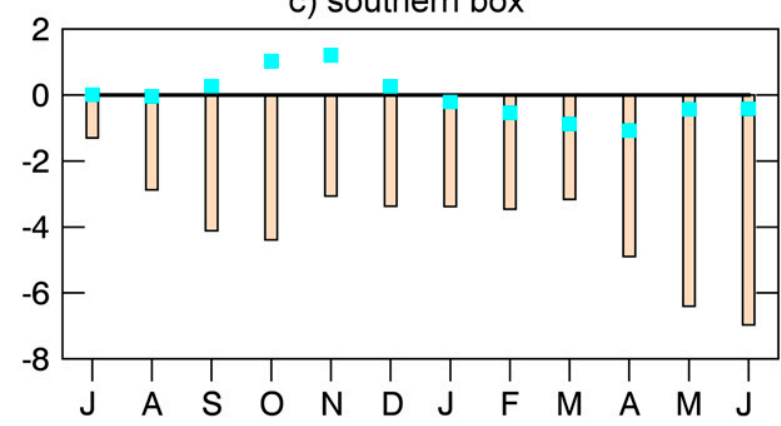

FIG. 8. Evolution of the accumulated monthly anomalies of $\mid\left(\right.$ E-P)i10 $<0 \mid$ (in $\mathrm{mm} \mathrm{day}^{-1}$ ) during July 2016-June 2017 for (a) the target region (TR; delimited colored regions in Fig. 2a), (b) the northern European box, and (c) the southern European box (Fig. 2a). Colored symbols and lines respectively represent the different oceanic and continental moisture sources of each region: TR (target region), AF (northern Africa), EU (continental areas over Europe), BS (Baltic Sea), NS (Nordic Seas), MS (Mediterranean Sea), and ATL (Atlantic). Note that the TR sink is also detected as a moisture source. Bars indicate the corresponding evolution of the accumulated 1-month time scale SPEI averaged over the given region.

The Atlantic also played a dominant contribution to the moisture loss in the northern and southern boxes, but the regions displayed some remarkable differences. For the northern box, the Atlantic source experienced a dramatic reduction in moisture input of more than $60 \%$ when integrated over the period of analysis (Fig. 8b). This accounted for more than $95 \%$ of the net moisture anomalies in that region (not shown). On the other hand, 
the net Atlantic moisture supply to the southern box was $90 \%$ of that expected from the climatology (Fig. $8 \mathrm{c}$ ) and the remaining sources are not able to explain the extreme SPEI in this region either (not shown). Indeed, the monthly evolution of SPEI during the drought does not follow that of the moisture anomalies for any source of the southern box, including the Atlantic one (Fig. 8c). There are several possible explanations for this lack of agreement. First, precipitation depends not only on moisture availability (i.e., precipitable water) but also on the occurrence of favorable dynamical conditions triggering precipitation. Thus, the dynamics (e.g., the above reported recurrence of subtropical ridges) could have prevented precipitation in the region, as expected, despite the presence of available moisture. Second, moisture gains by enhanced evapotranspiration within the region could have partially offset the moisture losses associated with precipitation (recycling), which can be very relevant even in dry environments and conditions (Miralles et al. 2016).

In summary, the drought severity in northwestern/ central Europe is in agreement with the reported deficits in the moisture supply from the Atlantic, which are translated into precipitation decreases and stronger responses in the SPI therein. On the contrary, the dry conditions in the south are not fully explained by reduced supply from moisture sources. As the SPEI is controlled by both precipitation and AED, these results suggest a primary role of precipitation in the former region and of $\mathrm{AED}$ in the latter one.

\section{b. AED-related anomalies}

The SPEI adds information about AED to the precipitation anomalies already accounted for by the SPI. As such, the difference between SPEI and SPI provides a rough estimate of the contribution of anomalies in the atmospheric evaporative demand (e.g., Stagge et al. 2017). This difference is shown in Fig. 2c for the drought event, displaying negative values over southern Europe (i.e., SPEI values considerably more negative than SPI values). In fact, the difference between the SPEI and SPI was record-breaking for Iberia and southern France (Fig. 2c), revealing a prominent role of enhanced AED in exacerbating the drought severity over southwestern Europe. Under the stable warm conditions associated with high pressure systems (section 4), AED was probably reinforced by land-atmosphere feedbacks via suppressed latent heat fluxes and enhanced sensible heat fluxes, contributing to exacerbating the drought, as suggested by previous studies (Seneviratne et al. 2010; Hirschi et al. 2011; Teuling 2018).

Since the atmospheric evaporative demand used for the calculation of the SPEI is affected by different components (temperature, wind, insolation, relative humidity), we have analyzed their standardized anomalies for the drought event. Temperature emerges as the variable with the largest anomalies, reaching record values for the period 1979-2017 over a large area of Iberia (Fig. 4b) where the difference between SPEI and SPI is maximum (Fig. 2c). The standardized anomalies are not so high for the rest of SPEI components (not shown), but eventually important in some regions. It should be stressed that these components do not contribute equally to AED given the nonlinear character of the FAO-56 Penman-Monteith equation and the differences in AED sensitivity to the atmospheric variables as a function of the climate conditions. This makes it difficult to quantify the role of each SPEI component from its observed anomalies.

Therefore, we have designed a partitioning approach to understand the role of the different evapotranspiration components in the severity of this drought. For each component, we have used its climatological values to recalculate the 12-month SPEI during the drought event. The contribution of a given component is defined as the difference between the actual SPEI and that inferred from the climatology. Figure 9 summarizes the dominant component (i.e., the one with largest contribution to the negative SPEI during the drought event) for each grid point of the region. The results reveal that precipitation, mean temperature, and sunshine duration were the SPEI components that contributed the most to the magnitude of the observed drought severity (see the separate contribution of each component in Fig. S5). It must be stressed that in some areas, several components played an appreciable and similar role (stippling in Fig. 9). For instance, eastern Europe was mainly affected by increased mean temperature and sunshine duration, whereas the contribution of precipitation together with these two components was quite relevant in France and southern Scandinavia. Nevertheless, there is a clear spatial distribution for the dominant component. Precipitation was the main driver of drought severity over the west of the British Isles, the Benelux region, and large parts of France, Germany, and Switzerland, in agreement with the results derived from the SPI (Fig. 2b). The drought in the northernmost part of the domain was mainly dominated by the radiative component (measured here by means of the sunshine duration). With the exception of Italy, temperature was the variable with the largest impact in southern Europe, including most of Iberia and southern France, as well as in some areas of eastern Europe. This stresses the key role of the thermodynamic component in the drought severity over southern Europe. 


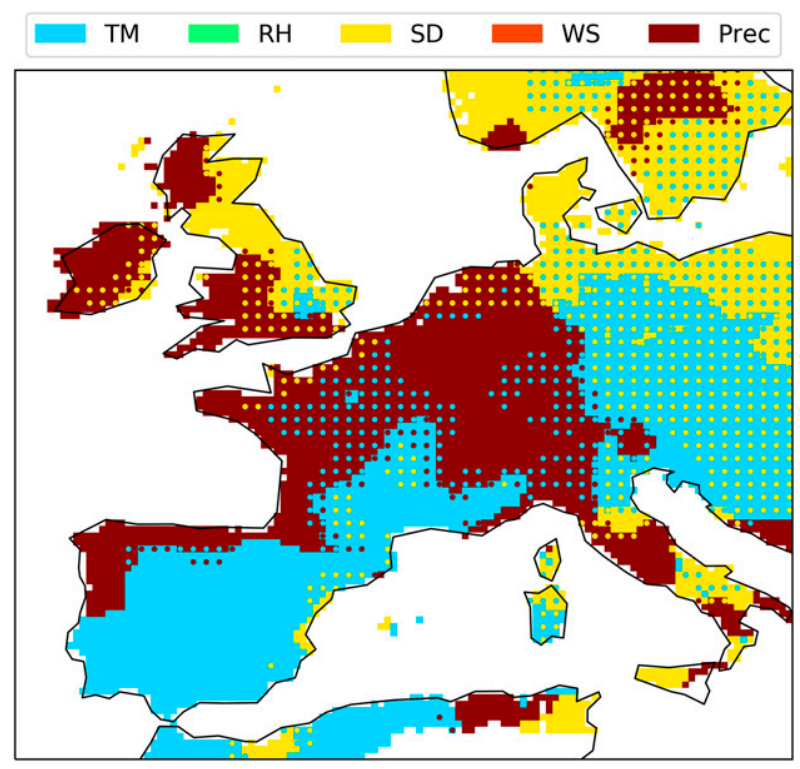

FIG. 9. Map displaying the dominant component (shading) of the 12-month SPEI value in June 2017, defined as the one with the largest difference between the actual SPEI and the SPEI calculated with 1970-2010 climatological values of that component. Dots indicate the grid points where the second largest component had an appreciable contribution (SPEI difference below -1.0 and at least $70 \%$ of that for the dominant component). Colors indicate the different components: daily-mean temperature (TM), relative humidity (RH), sunshine duration (SD), wind speed (WS), and precipitation (Prec).

The fingerprints and varying influences of each component across Europe are in good agreement with the dynamical signatures described in section 4 . The key role of precipitation deficit and increased radiation in the drought severity over northwestern/central Europe is well explained by the enhanced occurrence of high-latitude blocks, which divert the storm tracks all year round, thus leading to clear skies and precipitation reductions beneath the blocking high (Sousa et al. 2017). Conversely, the blocking signal in temperature varies depending on the season and the characteristics of the block (Sousa et al. 2018). On the other hand, subtropical ridges are more transient than blocks and tend to occur in southern regions, where precipitation totals are scarce as compared to those in central Europe. As a consequence, their most striking signature is an outstanding localized increase in temperature irrespective of the season when they occur (Sousa et al. 2018), in agreement with a more decisive role of temperature anomalies in the southern drying.

According to Stagge et al. (2017), the role of the AED in European droughts has increased since the 1980s and this trend is expected to continue, mostly due to global warming. In this context, we have assessed whether recent trends may have exacerbated this event. To do so, we have followed the analog method, as described by Wilcox et al. (2018) and references therein. We first computed analogs of the atmospheric circulation over a region with significant circulation anomalies $\left(40^{\circ}-65^{\circ} \mathrm{N}\right.$, $20^{\circ} \mathrm{W}-30^{\circ} \mathrm{E}$ ) for each day of the July 2016-June 2017 period, by using daily Z500 anomalies from two separate subperiods: 1948-84 (P0 hereafter) and 1985-2018 (P1; excluding July 2016-June 2017). Note that the NCEPNCAR reanalysis (Kalnay et al. 1996) was used for these analyses given that it covers a longer period than that of ERA-Interim. The best 20 analogs of each day were selected based on the root-mean-square differences. From these flow analogs, we reconstructed the target variable for each day between July 2016 and June 2017 by randomly picking one of the best 20 analogs of Z500 in the two subperiods. Hence we simulated "uchronic" trajectories of the target variable for two subperiods, both consistent with the atmospheric circulation that prevailed in 2016/17. Those trajectories were then averaged over the period between July 2016 and June 2017. The process was repeated 10000 times, allowing us to build the probability distributions of the target variable conditioned on the observed atmospheric circulation. By using flow analogs from different subperiods, we can evaluate how the simulated target variable under present conditions (P1) would have been in the past (P0).

Because of the lack of daily SPEI values, we used soil moisture content as the target variable, which is also affected by both precipitation and AED. Indeed, given Bouchet's complementary relationship (Bouchet 1963; Brutsaert and Parlange 1998), actual evapotranspiration $\left(\mathrm{ET}_{a}\right)$ affects AED via the surface sensible and latent heat fluxes, which are strongly driven by soil water availability (Seneviratne et al. 2010; Teuling et al. 2013; Teuling 2018). NCEP-NCAR daily volumetric soil water content at $0-10 \mathrm{~cm}$ below ground level was averaged for a region including Iberia and France $\left(36^{\circ}-52^{\circ} \mathrm{N}, 10^{\circ} \mathrm{W}-\right.$ $\left.8^{\circ} \mathrm{E}\right)$, where the effect of temperature and precipitation on SPEI was remarkable. Although this field has some biases, its long-term monthly variations have been verified to yield a reasonable phasing and are correlated to relevant atmospheric variables (Lu et al. 2005). Note also that we will not discuss the values of soil moisture per se, but the differences between two subperiods.

Figure 10 shows the resulting $\mathrm{P} 0$ and $\mathrm{P} 1$ probability distributions of regional volumetric soil moisture averaged over July 2016-June 2017 and for the four seasons in that period (from July-September 2016 to April-June 2017). There is little overlap between the annual distributions for $\mathrm{P} 0$ and $\mathrm{P} 1$, with a significant decrease in soil moisture from the past to the present period (black boxplots). As such, under similar atmospheric circulation, we can expect a stronger reduction in soil water 


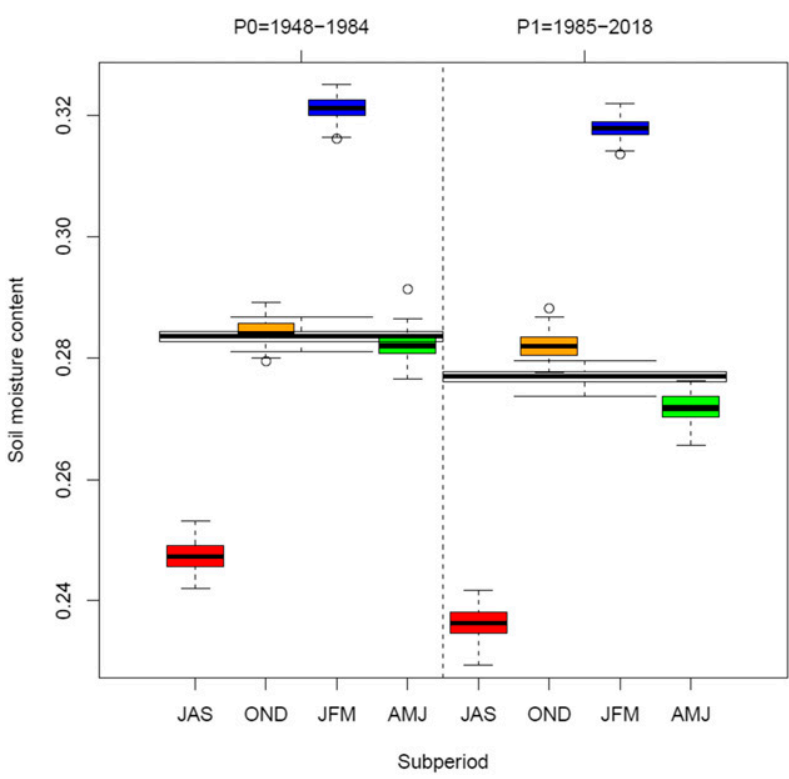

FIG. 10. Boxplots with the probability distributions of the daily mean volumetric soil moisture content (dimensionless) within 0 $10 \mathrm{~cm}$ below ground level, conditional on the atmospheric circulation during July 2016-June 2017. These have been calculated by using atmospheric flow analogs from two subperiods: 1948-84 (P0) and 1985-2018, excluding the period of study (P1). The boxes extend from the lower (Q1) to the upper (Q3) quartile values of the data, with a horizontal line indicating the median. The whiskers extend from the box to show the range of the data from Q1 $-1.53 \times$ IQR to $\mathrm{Q} 3+1.5 \times \mathrm{IQR}$, with IQR being the interquartile range. Outliers are shown with circles. The wide black boxplots are for the entire year (July 2016-June 2017). The colored boxplots are for the seasons in that period (July-September 2016: red; October-December 2016: orange; January-March 2017: blue; April-June 2017: green).

content now than in the past (i.e., the atmospheric circulation observed during the drought event would have caused weaker soil water anomalies and a less severe drought in the past). This is in agreement with a decreasing trend in soil water content over that area for the 1948-2018 reanalysis period. Since precipitation experiences large interannual variability over the region, the differences between subperiods are better explained by temperature trends causing enhanced evapotranspiration and reduced soil water content. Indeed, the largest differences of soil moisture between the two subperiods occur in summer (red boxplots) and spring (green boxplots), coinciding with the seasons of maximum warming trends (e.g., Stine et al. 2009; Cohen et al. 2012).

\section{Conclusions and discussion}

We have analyzed the record-breaking drought that affected most of western Europe during the July 2016-June
2017 period. We have used two indices to characterize this event. The standardized precipitation index (SPI) only considers precipitation, while the standardized precipitation-evapotranspiration index (SPEI) also takes into account the atmospheric evaporative demand (AED), following a robust physical approach based on the FAO-56 Penman-Monteith equation, which considers sunshine duration, temperature, surface wind speed, and relative humidity as inputs. The main conclusions can be summarized as follows:

- The analysis of the SPEI proves that this drought was outstanding in terms of magnitude and extension, arising as the most severe event in western Europe since at least 1979. Such strong anomalies are not so evident from the SPI values, in particular for southern Europe.

- Unlike previous droughts, which often occur either in the northwest/center or in the south of the continent, this event affected both, being the one with the first and second largest negative SPEI values averaged south and north of $47.5^{\circ} \mathrm{N}$, respectively, during the 1979-2017 period.

- The record-breaking Z500 anomalies are the most relevant dynamical feature of this episode, indicating weakened zonal circulation and enhanced high pressure systems during the whole episode. Further analyses reveal a concatenation of subtropical ridges and high-latitude blocks, which explained the unusual spatial distribution of this event. Overall, the former exacerbated the drought event in southern regions, whereas the latter contributed mostly to the dry conditions in northwestern/central Europe.

- The drought was concurrent with a significant decrease in moisture transport from the Atlantic Ocean. The reduction in the moisture contribution from this source is also key to explaining the dry conditions in the northwestern/central European regions, where the SPI indicates drier conditions than the SPEI. This is in agreement with a leading role of decreased precipitation and enhanced sunshine duration (typical signatures of high-latitude blocks) in the drought severity over northwestern/central Europe.

- The anomalies in moisture supply cannot fully explain the dry conditions observed in southern European regions, suggesting a major role of AED in this area. This is also evidenced by the stronger sensitivity of the SPEI to capture the severity of the drought in the south. Further analyses have revealed that warm temperature anomalies, typically associated with subtropical ridges, were a major driver of the dry conditions there.

In summary, although drought conditions persisted over all western Europe during the 2016/17 episode, drying in southern (northern) subregions was to a large 
extent of thermodynamic (dynamic) origin. Overall, several mechanisms acted differently during the whole year to produce this record-breaking event, with higher relevance of the precipitation-related dynamics in central Europe and of AED in the south. We also show that recent trends, including those in temperature, have exacerbated the severity of the July 2016-June 2017 drought event, and that the role of AED was key in hitting record values, at least in the south. The 2016/17 drought episode could represent an example of future European droughts due to the enhanced role of thermodynamics (Fischer et al. 2007; Seneviratne et al. 2013; Teuling et al. 2013; Berg et al. 2016) in altering the typical north-south dipole pattern of droughts triggered by dynamical mechanisms (i.e., the NAO; Sherwood and Fu 2014; Santos et al. 2016; Vicente-Serrano et al. 2018). Still, our results indicate a key role of dynamics (highlatitude blocks and subtropical ridges) in driving the precipitation and temperature anomalies that controlled drought severity during the 2016/17 drought. In this sense, future changes in the regional occurrence of high pressure systems are uncertain (e.g., Woollings et al. 2018 and references therein). More generally, the confidence in circulation-related aspects of climate change is low (Shepherd 2014), due to the large amount of natural variability on regional scales and inherent model deficiencies (Deser et al. 2012; Christensen et al. 2013). The intermodel spread in future projections for the Euro-Atlantic region is partly explained by differences in Arctic and tropical warming among models and their competing effects in the eddy-driven jet (e.g., Zappa and Shepherd 2017; Peings et al. 2018). Other important drivers of Euro-Atlantic circulation changes in model projections include the stratospheric polar vortex (e.g., Manzini et al. 2014) and North Atlantic SSTs (e.g., Woollings et al. 2012). These uncertainties affect the projected changes in the likelihood of unusual, long-lasting sequences of weather systems, as those reported herein. Therefore, future studies should address the relative contribution of these drivers to regional dynamical changes that are relevant to European droughts.

Acknowledgments. J. M. G-P. was supported by the predoctoral research grant awarded by the Spanish Ministerio de Educación, Cultura y Deporte (FPU16/ 01972). C.O. acknowledges funding by the Ramón y Cajal Programme (Grant RYC-2014-15036) and the STEADY project (Grant CGL2017-83198-R) funded by the Spanish Ministerio de Economía y Competitividad. S.M.V-S. was supported by the DESEMON research project funded by the Spanish Ministerio de Economía y Competitividad and FEDER (Grant CGL2014-52135C03-01), the IMDROFLOOD project financed by the
Water Works 2014 co-funded call of the European Commission (Grant PCIN-2015-220), and the INDECIS project, which is part of ERA4CS, and ERA-NET initiated by JPI Climate, and funded by FORMAS (SE), DLR (DE), BMWFW (AT), IFD (DK), MINECO (ES), ANR (FR) with co-funding by the European Union (Grant 690462). R.N., L.G. and R.S. were partially supported by Xunta de Galicia under Project ED431C 2017/64-GRC "Programa de Consolidación e Estructuración de Unidades de Investigación Competitivas (Grupos de Referencia Competitiva)." R.N and L.G were also supported by Water JPI-WaterWorks Programme under project Improving Drought and Flood Early Warning, Forecasting and Mitigation (IMDROFLOOD) (Code: PCIN-2015-243). L.G. was also supported by the Spanish Government and FEDER through the SETH project (Grant CGL201460849-JIN). R.S. would like to acknowledge funding by the Xunta of Galicia, Spain, in support of his doctoral research. P.Y. was supported by the ERC Grant 338965-A2C2. We acknowledge the E-OBS dataset from the EU-FP6 project ENSEMBLES (http://ensembleseu.metoffice.com) and the data providers in the ECA\&D project (http://www.ecad.eu), as well as the GPCC monthly land-surface precipitation dataset (https:// www.dwd.de/EN/ourservices/gpcc/gpcc.html). ERA data products provided courtesy of ECMWF. NCEPNCAR reanalysis data were provided by the NOAA/ OAR/ESRL PSD, Boulder, Colorado, USA, from their web site at http://www.esrl.noaa.gov/psd/. The authors thank two anonymous reviewers for their useful comments.

\section{REFERENCES}

Allen, R.G., L.S. Pereira, D. Raes, and M. Smith, 1998: Crop evapotranspiration: Guidelines for computing crop water requirements. Food and Agricultural Organization (FAO) Irrigation and Drainage Paper 56, 300 pp., http://www.fao.org/3/ X0490E/X0490E00.htm.

Barriopedro, D., R. García-Herrera, A. R. Lupo, and E. Hernández, 2006: A climatology of Northern Hemisphere blocking. J. Climate, 19, 1042-1063, https://doi.org/ 10.1175/JCLI3678.1.

__, _—, and R. M. Trigo, 2010: Application of blocking diagnosis methods to general circulation models. Part I: A novel detection scheme. Climate Dyn., 35, 1373-1391, https:// doi.org/10.1007/s00382-010-0767-5.

BBC, 2017a: Italy drought: 11 regions poised for state of emergency. BBC, 2 August 2017, accessed 7 January 2019, http:// www.bbc.com/news/world-europe-40803619.

— $2017 \mathrm{~b}$ : Italy wildfires: Tourists rescued by boat from Calampiso. BBC, 13 July 2017, accessed 7 January 2019, http:// www.bbc.com/news/world-europe-40590090.

Berg, A., and Coauthors, 2016: Land-atmosphere feedbacks amplify aridity increase over land under global warming. Nat. Climate Change, 6, 869-874, https://doi.org/10.1038/nclimate3029. 
Bisselink, B., and A. J. Dolman, 2008: Precipitation recycling: Moisture sources over Europe using ERA-40 data. J. Hydrometeor., 9, 1073-1083, https://doi.org/10.1175/2008JHM962.1.

Bissolli, P., and Coauthors, 2017: Europe and the Middle East [in "State of the Climate in 2016"]. Bull. Amer. Meteor. Soc., 98 (8), S201S212., https://doi.org/10.1175/2017BAMSStateoftheClimate.1.

— of the Climate in 2017']. Bull. Amer. Meteor. Soc., 99 (8), S222-S232, doi:10.1175/2018BAMSStateoftheClimate.1.

Bouchet, R. J., 1963: Evapotranspiration réelle evapotranspiration potentielle, signification climatique. IAHS Publ., 62 , 134-142.

Brutsaert, W., and M. Parlange, 1998: Hydrologic cycle explains the evaporation paradox. Nature, 396, 30, https://doi.org/ $10.1038 / 23845$.

Christensen, J. H., K. Krishna Kumar, and E. Aldrian, 2013: Climate phenomena and their relevance for future regional climate change. Climate Change 2013: The Physical Science Basis, T. F. Stocker et al., Eds., Cambridge University Press, 1217-1308.

Ciais, P., and Coauthors, 2005: Europe-wide reduction in primary productivity caused by the heat and drought in 2003. Nature, 437, 529-533, https://doi.org/10.1038/nature03972.

Cohen, J. L., J. C. Furtado, M. Barlow, V. Alexeev, and J. E. Cherry, 2012: Asymmetric seasonal temperature trends. Geophys. Res. Lett., 39, L04705, https://doi.org/10.1029/2011GL050582.

Dee, D. P., and Coauthors, 2011: The ERA-Interim reanalysis: Configuration and performance of the data assimilation system. Quart. J. Roy. Meteor. Soc., 137, 553-597, https://doi.org/ 10.1002/qj.828.

Deser, C., A. S. Phillips, V. Bourdette, and H. Teng, 2012: Uncertainty in climate change projections: The role of internal variability. Climate Dyn., 38, 527-546, https://doi.org/10.1007/ s00382-010-0977-x.

Drumond, A., L. Gimeno, R. Nieto, R. M. Trigo, and S. M. Vicente-Serrano, 2017: Drought episodes in the climatological sinks of the Mediterranean moisture source: The role of moisture transport. Global Planet. Change, 151, 4-14, https:// doi.org/10.1016/j.gloplacha.2016.12.004.

DW, 2017: Dozens killed in Portugal forest fire. Deutsche Welle, accessed 7 January 2018, http://www.dw.com/en/dozenskilled-in-portugal-forest-fire/a-39295530.

ECMWF, 2017: The European State of the Climate 2017. Copernicus Services of the European Centre for Medium-Range Weather Forecasts, https://climate.copernicus.eu/CopernicusESC.

El País, 2017a: La extrema sequía pasa factura al recibo de la luz. El País, 13 November 2017, accessed 7 January 2019, https://elpais.com/economia/2017/11/10/actualidad/1510335366_ 495010.html.

_ 2017b: El gran desplome hidroeléctrico. El País, 13 November 2017, accessed 7 January 2019, https://politica.elpais.com/politica/ 2017/10/14/actualidad/1508007106_421979.html.

Fischer, E. M., S. I. Seneviratne, P. L. Vidale, D. Lüthi, and C. Schär, 2007: Soil moisture-atmosphere interactions during the 2003 European summer heat wave. J. Climate, 20, 50815099, https://doi.org/10.1175/JCLI4288.1.

Fleig, A. K., L. M. Tallaksen, H. Hisdal, and D. M. Hannah, 2011: Regional hydrological drought in north-western Europe: Linking a new regional drought area index with weather types. Hydrol. Processes, 25, 1163-1179, https://doi.org/ 10.1002/hyp.7644.

Gimeno, L., and Coauthors, 2012: Oceanic and terrestrial sources of continental precipitation. Rev. Geophys., 50, RG4003, https://doi.org/10.1029/2012RG000389.
Gudmundsson, L., S. I. Seneviratne, and X. Zhang, 2017: Anthropogenic climate change detected in European renewable freshwater resources. Nat. Climate Change, 7, 813-816, https:// doi.org/10.1038/nclimate3416.

Haylock, M. R., N. Hofstra, A. Klein Tank, E. J. Klok, P. D. Jones, and M. New, 2008: A European daily high-resolution gridded data set of surface temperature and precipitation for 1950 2006. J. Geophys. Res. Atmos., 113, D20119, https://doi.org/ 10.1029/2008JD010201.

Heim, R. R., Jr., 2002: A review of twentieth-century drought indices used in the United States. Bull. Amer. Meteor. Soc., 83, 1149-1165, https://doi.org/10.1175/1520-0477-83.8.1149.

Hirschi, M., and Coauthors, 2011: Observational evidence for soilmoisture impact on hot extremes in southeastern Europe. Nat. Geosci., 4, 17-21, https://doi.org/10.1038/ngeo1032.

Hoerling, M., J. Eischeid, J. Perlwitz, X. Quan, T. Zhang, and P. Pegion, 2012: On the increased frequency of Mediterranean drought. J. Climate, 25, 2146-2161, https://doi.org/10.1175/ JCLI-D-11-00296.1.

Kalnay, E., and Coauthors, 1996: The NCEP/NCAR 40-Year Reanalysis Project. Bull. Amer. Meteor. Soc., 77, 437-471, https:// doi.org/10.1175/1520-0477(1996)077<0437:TNYRP>2.0.CO;2.

Lu, C., M. Kanamitsu, J. O. Roads, W. Ebisuzaki, K. E. Mitchell, and D. Lohmann, 2005: Evaluation of soil moisture in the NCEPNCAR and NCEP-DOE global reanalyses. J. Hydrometeor., 6, 391-408, https://doi.org/10.1175/JHM427.1.

Manzini, E., and Coauthors, 2014: Northern winter climate change: Assessment of uncertainty in CMIP5 projections related to stratosphere-troposphere coupling. J. Geophys. Res. Atmos., 119, 7979-7998, https://doi.org/10.1002/2013JD021403.

McKee, T. B., N. J. Doesken, and J. Kleist, 1993: The relationship of drought frequency and duration to time scales. Proc. Eighth Conf. on Applied Climatology, Anaheim, CA, Amer. Meteor. Soc., 179-183.

McVicar, T. R., and Coauthors, 2012: Global review and synthesis of trends in observed terrestrial near-surface wind speeds: Implications for evaporation. J. Hydrol., 416-417, 182-205, https://doi.org/10.1016/j.jhydrol.2011.10.024.

Miralles, D. G., A. J. Teuling, C. C. van Heerwaarden, and J. Vilà-Guerau de Arellano, 2014: Mega-heatwave temperatures due to combined soil desiccation and atmospheric heat accumulation. Nat. Geosci., 7, 345-349, https://doi.org/ $10.1038 /$ ngeo 2141 .

— , and Coauthors, 2016: Contribution of water-limited ecoregions to their own supply of rainfall. Environ. Res. Lett., 11, 124007, https://doi.org/10.1088/1748-9326/11/12/124007.

— P. Gentine, S. I. Seneviratne, and A. J. Teuling, 2019: Landatmospheric feedbacks during droughts and heatwaves: State of the science and current challenges. Ann. N. Y. Acad. Sci., 1436, 19-35, https://doi.org/10.1111/nyas.13912.

Mishra, A. K., and V. P. Singh, 2011: Drought modeling-A review. J. Hydrol., 403, 157-175, https://doi.org/10.1016/ j.jhydrol.2011.03.049.

Nieto, R., R. Castillo, A. Drumond, and L. Gimeno, 2014: A catalog of moisture sources for continental climatic regions. Water Resour. Res., 50, 5322-5328, https://doi.org/10.1002/ 2013WR013901.

Numaguti, A., 1999: Origin and recycling processes of precipitating water over the Eurasian continent: Experiments using an atmospheric general circulation model. J. Geophys. Res., 104, 1957-1972, https://doi.org/10.1029/1998JD200026.

Ogi, M., K. Yamazaki, and Y. Tachibana, 2004: The summertime annular mode in the Northern Hemisphere and its linkage 
to the winter mode. J. Geophys. Res., 109, D20114, https:// doi.org/10.1029/2004JD004514.

Palmer, W. C., 1965: Meteorological drought. U.S. Department of Commerce, Weather Bureau Research Paper 45, 58 pp.

Pausas, J. G., 2004: Changes in fire and climate in the eastern Iberian Peninsula (Mediterranean basin). Climatic Change, 63, 337-350, https://doi.org/10.1023/B:CLIM.0000018508.94901.9c.

Peings, Y., J. Cattiaux, S. J. Vavrus, and G. Magnusdottir, 2018: Projected squeezing of the wintertime North-Atlantic jet. Environ. Res. Lett., 13, 074016, https://doi.org/10.1088/17489326/aacc79.

Reuters, 2017: One of worst droughts in decades devastates South Europe crops. Reuters, 14 July 2017, accessed 7 January 2019, https://www.reuters.com/article/us-europe-farming-drought/ one-of-worst-droughts-in-decades-devastates-south-europecrops-idUSKBN19Z1XW.

Sánchez-Benítez, A., R. García-Herrera, D. Barriopedro, P. M. Sousa, and R. M. Trigo, 2018: June 2017: The earliest European summer mega-heatwave of reanalysis period. Geophys. Res. Lett., 45, 1955-1962, https://doi.org/10.1002/ 2018GL077253.

Santos, J. A., J. G. Pinto, and U. Ulbrich, 2009: On the development of strong ridge episodes over the eastern North Atlantic. Geophys. Res. Lett., 36, L17804, https://doi.org/ 10.1029/2009GL039086.

_ - M. Belo-Pereira, H. Fraga, and J. G. Pinto, 2016: Understanding climate change projections for precipitation over western Europe with a weather typing approach. J. Geophys. Res. Atmos., 121, 1170-1189, https://doi.org/10.1002/2015JD024399.

Schneider, U., A. Becker, P. Finger, A. Meyer-Christoffer, B. Rudolf and M. Ziese, 2011: GPCC full data reanalysis version 6.0 at $0.5^{\circ}$ : Monthly land-surface precipitation from raingauges built on GTS-based and historic data. Accessed December 2018, https://doi.org/10.5676/DWD_GPCC/FD_M_V7_050.

Schubert, S. D., and Coauthors, 2016: Global meteorological drought: A synthesis of current understanding with a focus on SST drivers of precipitation deficits. J. Climate, 29, 39894019, https://doi.org/10.1175/JCLI-D-15-0452.1.

Seneviratne, S. I., T. Corti, E. L. Davin, M. Hirschi, E. B. Jaeger, I. Lehner, B. Orlowsky, and A. J. Teuling, 2010: Investigating soil moisture-climate interactions in a changing climate: A review. Earth-Sci. Rev., 99, 125-161, https://doi.org/10.1016/ j.earscirev.2010.02.004.

—_, and Coauthors, 2013: Impact of soil moisture-climate feedbacks on CMIP5 projections: First results from the GLACE-CMIP5 experiment. Geophys. Res. Lett., 40, 5212 5217, https://doi.org/10.1002/grl.50956.

Shepherd, T. G., 2014: Atmospheric circulation as a source of uncertainty in climate change projections. Nat. Geosci., 7, 703-708, https://doi.org/10.1038/ngeo2253.

Sherwood, S., and Q. Fu, 2014: A drier future? Science, 343, 737739, https://doi.org/10.1126/science.1247620.

Sousa, P. M., R. M. Trigo, P. Aizpurua, R. Nieto, L. Gimeno, and R. García-Herrera, 2011: Trends and extremes of drought indices throughout the 20th century in the Mediterranean. Nat. Hazards Earth Syst. Sci., 11, 33-51, https://doi.org/ 10.5194/nhess-11-33-2011.

, D. Barriopedro, P. M. M. Soares, A. M. Ramos, and M. L. R. Liberato, 2017: Responses of European precipitation distributions and regimes to different blocking locations. Climate Dyn., 48, 1141-1160, https://doi.org/10.1007/s00382-016-3132-5.

, ——, - — - $\longrightarrow$, and J. A. Santos, 2018: European temperature responses to blocking and ridge regional patterns.
Climate Dyn., 50, 457-477, https://doi.org/10.1007/s00382017-3620-2.

Spinoni, J., G. Naumann, J. V. Vogt, and P. Barbosa, 2015: European drought climatologies and trends based on a multi-indicator approach. Global Planet. Change, 127, 50-57, https://doi.org/ 10.1016/j.gloplacha.2015.01.012.

- _, - , and ——, 2017: Pan-European seasonal trends and recent changes of drought frequency and severity. Global Planet. Change, 148, 113-130, https://doi.org/10.1016/ j.gloplacha.2016.11.013.

Stagge, J. H., D. G. Kingston, L. M. Tallaksen, and D. M. Hannah, 2017: Observed drought indices show increasing divergence across Europe. Sci. Rep., 7, 14045, https://doi.org/10.1038/ s41598-017-14283-2.

Stine, A. R., P. Huybers, and I. Y. Fung, 2009: Changes in the phase of the annual cycle of surface temperature. Nature, 457, 435-440, https://doi.org/10.1038/nature07675.

Stohl, A., and P. James, 2004: A Lagrangian analysis of the atmospheric branch of the global water cycle. Part I: Method description, validation and demonstration for the August 2002 flooding in central Europe. J. Hydrometeor., 5, 656-678, https://doi.org/10.1175/ 1525-7541(2004)005<0656:ALAOTA > 2.0.CO;2.

$\longrightarrow$, and - 2005: A Lagrangian analysis of the atmospheric branch of the global water cycle. Part II: Moisture transports between Earth's ocean basins and river catchments. J. Hydrometeor., 6, 961-984, https://doi.org/10.1175/JHM470.1.

C. Forster, A. Frank, P. Seibert, and G. Wotawa, 2005: Technical note: The Lagrangian particle dispersion model FLEXPART version 6.2. Atmos. Chem. Phys., 5, 2461-2474, https://doi.org/10.5194/acp-5-2461-2005.

Stojanovic, M., A. Drumond, R. Nieto, and L. Gimeno, 2017: Moisture transport anomalies over the Danube River basin during two drought events: A Lagrangian analysis. Atmosphere, 8, 193, https://doi.org/10.3390/atmos8100193.

$-,-\longrightarrow, \ldots$, and -2018 : Anomalies in moisture supply during the 2003 drought event in Europe: A Lagrangian analysis. Water, 10, 467, https://doi.org/10.3390/w10040467.

Strosser, P., and Coauthors, 2012: Final report: Gap analysis of the Water Scarcity and Droughts Policy in the EU European Commission. European Commission, 206 pp., ec.europa.eu/ environment/water/quantity/pdf/WSDGapAnalysis.pdf.

Teuling, A. J., 2018: A hot future for European droughts. Nat. Climate Change, 8, 364-365, https://doi.org/10.1038/s41558018-0154-5.

_- and Coauthors, 2013: Evapotranspiration amplifies European summer drought. Geophys. Res. Lett., 40, 2071-2075, https://doi.org/10.1002/grl.50495.

The Connexion, 2017: Drought water restriction extended to 74 departments. The Connexion, 28 July 2017, accessed 7 January 2019, https://www.connexionfrance.com/French-news/Droughtwater-restriction-extended-to-74-departments.

Trigo, R. M., and Coauthors, 2013: The record winter drought of 2011-12 in the Iberian Peninsula [in "Explaining Extreme Events of 2012 from a Climate Perspective"]. Bull. Amer. Meteor. Soc., 94 (9), S41, https://doi.org/10.1175/BAMS-D-13-00085.1.

van der Ent, R. J., H. H. G. Savenije, B. Schaefli, and S. C. SteeleDunne, 2010: Origin and fate of atmospheric moisture over continents. Water Resour. Res., 46, W09525, https://doi.org/ 10.1029/2010WR009127.

Vicente-Serrano, S. M., and S. Beguería, 2016: Comment on "Candidate distributions for climatological drought indices (SPI and SPEI)" by James H. Stagge et al. Int. J. Climatol., 36, 2120-2131, https://doi.org/10.1002/joc.4474. 
and J. I. López-Moreno, 2010: A multiscalar drought index sensitive to global warming: The standardized precipitation evapotranspiration index. J. Climate, 23, 1696-1718, https://doi.org/10.1175/2009JCLI2909.1.

_ , and Coauthors, 2014: Evidence of increasing drought severity caused by temperature rise in southern Europe. Environ. Res. Lett., 9, 044001, https://doi.org/10.1088/1748-9326/ 9/4/044001.

_ - G. Van der Schrier, S. Beguería, C. Azorin-Molina, and J. I. Lopez-Moreno, 2015: Contribution of precipitation and reference evapotranspiration to drought indices under different climates. J. Hydrol., 526, 42-54, https://doi.org/10.1016/ j.jhydrol.2014.11.025.

- and Coauthors, 2018: Recent changes of relative humidity: Regional connection with land and ocean processes. Earth Syst. Dyn., 9, 915-937, https://doi.org/10.5194/esd-9915-2018.

Wells, N., S. Goddard, and M. J. Hayes, 2004: A self-calibrating Palmer Drought Severity Index. J. Climate, 17, 2335-2351, https://doi.org/10.1175/1520-0442(2004)017<2335:ASPDSI> 2.0.CO;2.
Wilcox, L. J., and Coauthors, 2018: Multiple perspectives on the attribution of the extreme European summer of 2012 to climate change. Climate Dyn., 50, 3537-3555, https://doi.org/ 10.1007/s00382-017-3822-7.

Wilhite, D., and R. Pulwarty, 2017: Drought and Water Crises: Integrating Science, Management, and Policy. 2nd ed. CRC Press, $542 \mathrm{pp}$.

Woollings, T., A. Hannachi, and B. Hoskins, 2010: Variability of the North Atlantic eddy-driven jet stream. Quart. J. Roy. Meteor. Soc., 136, 856-868, https://doi.org/10.1002/qj.625.

— J. M. Gregory, J. G. Pinto, M. Reyers, and D. J. Brayshaw, 2012: Response of the North Atlantic storm track to climate change shaped by ocean- atmosphere coupling. Nat. Geosci., 5, 313-317, https://doi.org/10.1038/ngeo1438.

- , and Coauthors, 2018: Blocking and its response to climate change. Curr. Climate Change Rep., 4, 287-300, https://doi.org/ 10.1007/s40641-018-0108-z.

Zappa, G., and T. Shepherd, 2017: Storylines of atmospheric circulation change for European regional climate impact assessment. J. Climate, 30, 6561-6577, https://doi.org/10.1175/ JCLI-D-16-0807.1. 